\title{
Improved In Vitro and In Vivo Biocompatibility of Graphene Oxide through Surface Modification: Poly(Acrylic Acid)- Functionalization is Superior to PEGylation
}

\author{
Ming Xu, ${ }^{\dagger, \#}$ Jianqiang Zhu, ${ }^{\dagger, \ddagger, \#}$ Fanfan Wang, ${ }^{\|}$Yunjing Xiong, ${ }^{\S}$ Yakun $\mathrm{Wu}^{\dagger}{ }^{\dagger}$ Qiuquan Wang, ${ }^{\S}$
} Jian Weng, ${ }^{*}, \$$ Zhihong Zhang, ${ }^{*}+$ Wei Chen,

${ }^{\dagger}$ State Key Laboratory of Environmental Chemistry and Ecotoxicology, Research Center for Eco-Environmental Sciences, Chinese Academy of Sciences, Beijing 100085, China

${ }^{*}$ Department of Urology, The Second Hospital of Tianjin Medical University, Tianjin Institute of Urology, Tianjin 300211, China

${ }^{\S}$ Research Center of Biomedical Engineering, Department of Biomaterials, College of Materials, Xiamen University, Xiamen 361005, China

"College of Environmental Science and Engineering, Ministry of Education Key Laboratory of Pollution Processes and Environmental Criteria, Tianjin Key Laboratory of Environmental Remediation and Pollution Control, Nankai University, Tianjin 300071, China

\section{Supporting Information}

ABSTRACT: The unique physicochemical properties of two-dimensional (2D) graphene oxide (GO) could greatly benefit the biomedical field; however, recent research demonstrated that GO could induce in vitro and in vivo toxicity. We determined the mechanism of GO induced toxicity, and our in vitro experiments revealed that pristine GO could impair cell membrane integrity and functions including regulation of membrane- and cytoskeletonassociated genes, membrane permeability, fluidity and ion channels. Furthermore, GO induced platelet depletion, pro-inflammatory response and pathological changes of lung and liver in mice. To improve the biocompatibility of pristine GO, we prepared a series of GO derivatives including aminated GO (GO- $\left.\mathrm{NH}_{2}\right)$, poly(acrylamide)-functionalized GO (GO-PAM), poly(acrylic acid)-functionalized GO (GO-PAA) and poly(ethylene glycol)-functionalized GO (GO-PEG), and compared their toxicity with pristine GO in vitro and in vivo. Among these GO derivatives, GO-PEG and GO-PAA induced less toxicity than pristine GO, and GO-PAA was the most biocompatible one in vitro and in vivo. The differences in biocompatibility were due to the differential compositions of protein corona, especially immunoglobulin $\mathrm{G}$ (IgG), formed on their surfaces that determine their cell membrane interaction and cellular uptake, the extent of platelet depletion in blood, thrombus formation under short-term exposure and the pro-inflammatory effects under long-term exposure. Overall, our combined data delineated the key molecular mechanisms underlying the in vivo and in vitro biological behaviors and toxicity of pristine GO, and identified a safer GO derivative that could be used for future applications.

KEYWORDS: graphene oxide, surface modification, derivatives, biocompatibility, biological mechanisms

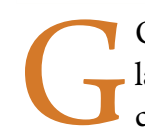

$\mathrm{O}$ and its derivatives have shown great promises in a large array of biomedical applications as drug delivery carriers, diagnostic imaging sensors, antimicrobial agents, etc. ${ }^{1-6}$ For example, as drug carriers, GO can bind antitumor drugs via $\pi-\pi$ stacking and hydrophobic interactions to improve the water solubility, bioavailability and overcome resistance of antitumor drugs. However, pristine graphene and GO have been shown to elicit adverse effects in vitro and in vivo including reactive oxygen species formation, DNA damage, cell apoptosis, pulmonary edema and granuloma formation, inflammatory cell infiltration, thrombus formation, delayed development in offspring, etc. ${ }^{7-15}$ The toxicity of GO hampers its application for medical purposes. In order to reduce the toxicity of GO and improve its in vivo biocompatibility, many

Received: October 19, 2015

Accepted: February 8, 2016

Published: February 8, 2016 
(a)
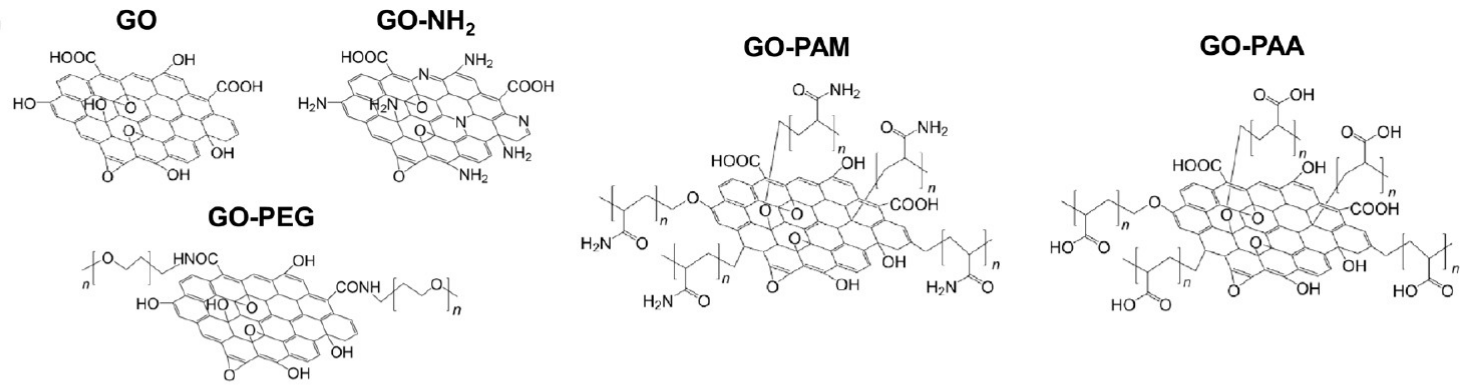

(b)
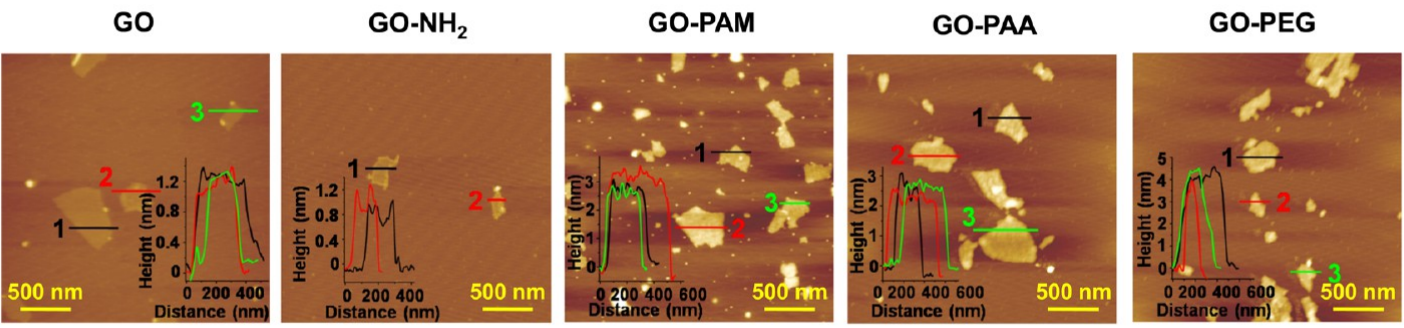

(c)
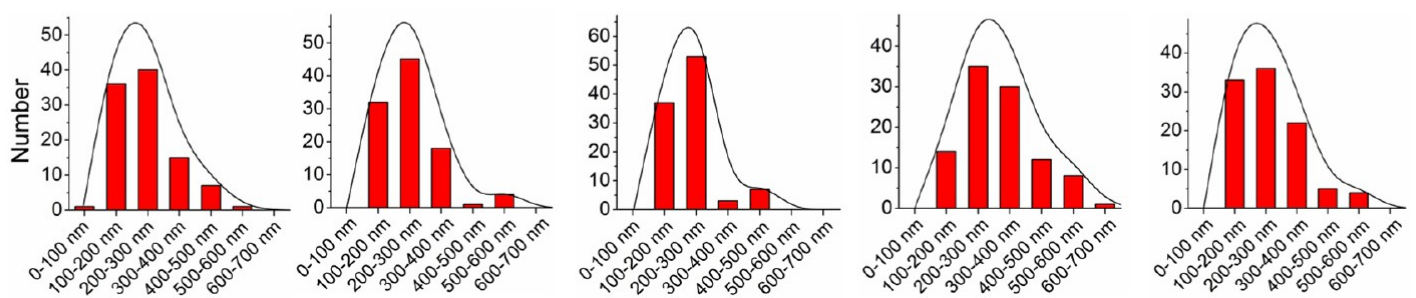

(d)
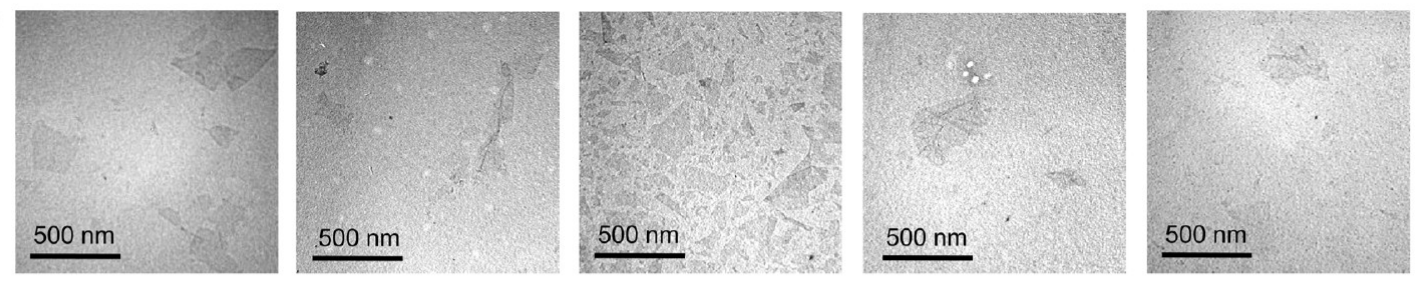

(e)
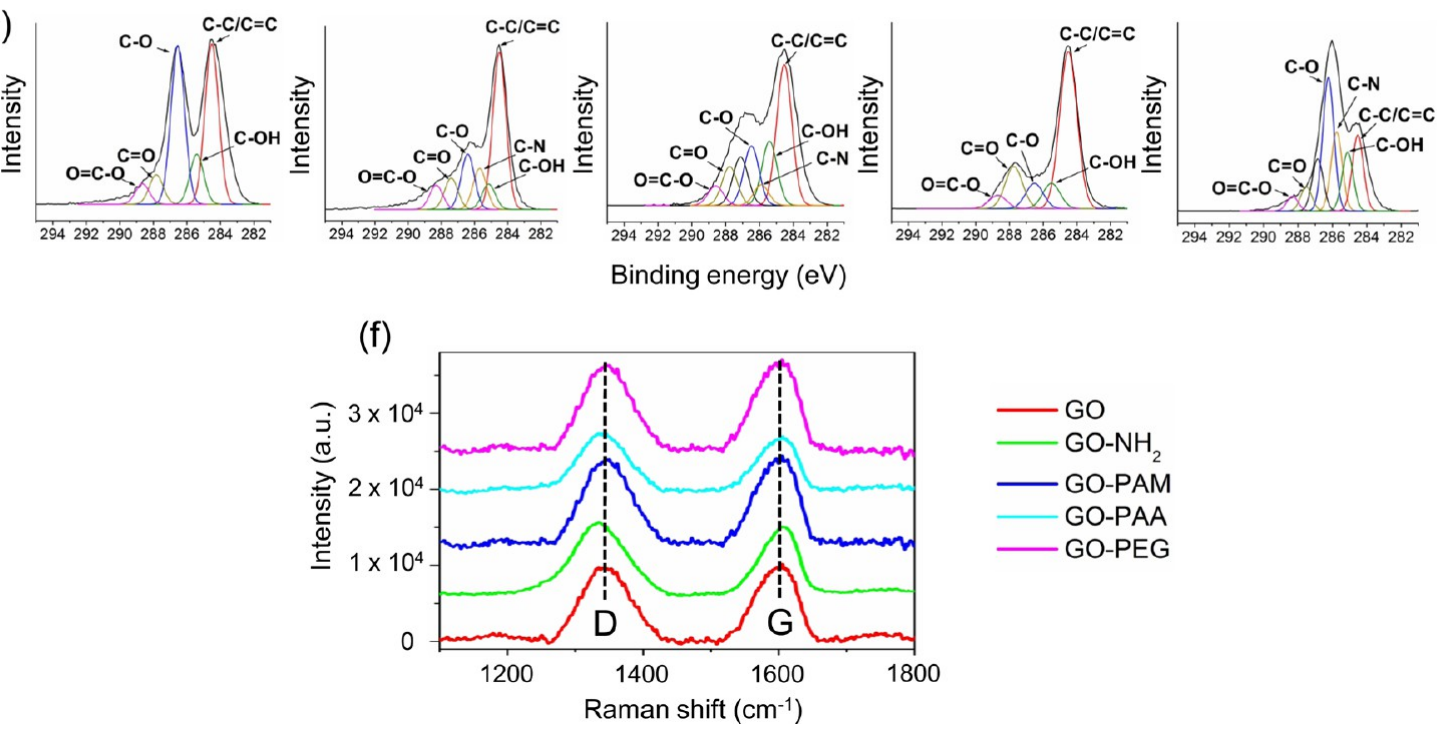

Figure 1. Chemical modifications of the same batch of parental GO (pristine GO) with functional groups or polymers. (a) Chemical structures of pristine GO and its derivatives, GO-NH${ }_{2}$, GO-PAM, GO-PAA and GO-PEG. (b) Representative AFM images with height profiles. (c) The size distribution of pristine GO, GO-NH, GO-PAM, GO-PAA and GO-PEG based on the AFM analysis. The histograms were developed by counting sheets for each sample $(n=100)$, with Gaussian fit curves in each histogram. (d) Representative TEM images, (e) C1 XPS spectra and (f) Raman spectra of GO, GO-NH $\mathrm{N}_{2}$, GO-PAM, GO-PAA and GO-PEG. 
challenges have to be addressed such as deciphering its toxicological mechanisms and development of safer GO materials.

The biocompatibility of GO is largely dependent on its intrinsic physicochemical properties including lateral size, thickness, stiffness and surface properties. ${ }^{5}$ Among these factors, surface properties (e.g., functional groups, charge, carbon/oxygen ratio and hydrophobicity) are crucial in determining the nature of the interaction between GO and biomolecules. Previous studies revealed that GO was highly thrombogenic and could induce aggregation of platelets, whereas amine-modified graphene did not incur such a effect on platelets, likely due to their different surface charges. ${ }^{11}$ Meanwhile, covalent oxidation $(\mathrm{O} / \mathrm{C}$ ratio) status of graphene surface was recognized to be a major contributor to oxidative stress, cytotoxicity, and pulmonary toxicity. ${ }^{10,13}$ To overcome these drawbacks of pristine GO, many efforts have been devoted to study its behaviors and toxicological mechanisms in vitro and in vivo, which can facilitate the development of the new GO derivatives with high biocompatibility for safer biomedical applications.

Surface modification is a commonly adopted approach to improve the biocompatibility of nanomaterials for safer biomedical applications. ${ }^{16}$ For instance, PEGylation has been preferentially used to modify nanomaterials to reduce nonspecific protein adsorption, preventing flocculation and opsonization, and subsequent complement activation. ${ }^{17}$ PEGylation is believed to be a safe approach in biological application, and it has already been used to improve the performance of GO. A recent study demonstrated PEG modified-GO resulted in higher survival rate of GO-treated BALB/c mice at $80 \mathrm{mg} / \mathrm{kg}$ by intravenously injection after 1 day, compared to pristine GO. ${ }^{18}$ However, the interactions between PEG and biomolecules remain to be fully understood. PEG was previously found to have the propensity to provoke blood clotting and clumping of cells. ${ }^{19}$ Moreover, PEG-specific immune response has been recently identified, showing that PEG modifiednanoparticles could induce the anti-PEG immunoglobulin $M$ antibody production. ${ }^{19-21}$ Besides PEGylation, other chemical functionalizations and polymer modifications of nanoparticles should be explored for the development of GO materials with improved biocompatibility, less immune response and longer blood circulation. $^{20}$

Although progress has been made regarding the biocompatibility and biosafety of GO after surface modifications under different biological settings, no systemic comparisons has been done in vitro and in vivo, which is especially important for future biomedical applications of these materials. ${ }^{22}$ The primary objective of the present study was to perform systemic comparison on the biocompatibility of several GO materials with different forms of surface modification, and to identify surface modifications that could increase the biocompatibility of GO for potential biomedical applications. We looked into the biological behaviors and mechanisms of pristine GO on cell membrane integrity and function in vitro, and platelet depletion, pro-inflammatory response and pathological changes of lung and liver in vivo. Afterward, biological effects in vitro and in vivo of several surface-modified GO materials, including GO- $\mathrm{NH}_{2}$, GO-PAM, GO-PAA and GO-PEG from the same starting GO material, were closely compared. GO-PEG and GO-PAA were found to induce less toxicity than pristine GO, GO-PAM and GO- $\mathrm{NH}_{2}$ due to their low protein adsorption in serum and weak interaction with macrophage, and PAA was the most biocompatible one compared to PEG in vitro and in vivo. Our combined findings may ultimately aid in the establishment of GO-based biomedical applications

\section{RESULTS AND DISCUSSION}

Synthesis and Characterization of GO Materials. Since GO possesses high content of oxygen groups (e.g., carbonyl, hydroxyl and epoxy groups) on the planar surfaces and the edges of the carbon sheets, these functional groups offer ideal sites for chemical modification. Here, the same starting pristine GO with high purity was chemically modified to obtain GO$\mathrm{NH}_{2}$, GO-PAM, GO-PAA and GO-PEG, according to the methods described previously. ${ }^{23-27}$ As shown in Figure 1a, PEG molecules were conjugated to the carboxylic acid groups on GO via carbodiimide catalyzed amide formation, while PAM and PAA on GO were introduced by free-radical polymerization. Among these chemical modifications, amino- and PEGmodified graphene materials have been reported to exhibit good biocompatibility in vitro and in vivo. ${ }^{11,18}$ For PAM and PAA, they were known to have good water solubility at room temperature that could prevent graphene from agglomeration and sedimentation. ${ }^{23}$ Nonetheless, little is known about the biological behaviors and biocompatibility of GO-PAM and GOPAA.

All GO materials were thoroughly characterized. First, SEM/ EDS (scan electron microscopy/energy dispersive spectrometer) and inductively coupled plasma mass spectrometry (ICPMS) were used to determine if there were significant impurities (e.g., $\mathrm{Cr}, \mathrm{As}, \mathrm{Cd}, \mathrm{Sb}, \mathrm{Pb}$ and $\mathrm{Hg}$ ) in $\mathrm{GO}$ samples. The results showed that the levels of impurities were below detection limit. Atomic force microscopy (AFM) showed similar lateral size distribution for these GO materials, with over $90 \%$ sheets in the range of 100 to $500 \mathrm{~nm}$ (Figure 1b,c), consistent with the results of dynamic light scattering (DLS) analysis (Table 1).

Table 1. Physicochemical Characterization of GO Materials

\begin{tabular}{|c|c|c|c|c|}
\hline & $\begin{array}{c}\text { hydrodynamic } \\
\text { diameter }^{a}(\mathrm{~nm})\end{array}$ & $\begin{array}{l}\text { thickness }{ }^{b} \\
(\mathrm{~nm})\end{array}$ & $I_{\mathrm{D}} / I_{\mathrm{G}}{ }^{c}$ & $\zeta_{(\mathrm{mV})}^{\zeta \text { potential }^{c}}$ \\
\hline GO & $201 \pm 9$ & $1.1 \pm 0.1$ & 0.999 & $-7.4 \pm 0.5$ \\
\hline $\begin{array}{l}\mathrm{GO}- \\
\mathrm{NH}_{2}\end{array}$ & $251 \pm 1$ & $1.2 \pm 0.2$ & 1.067 & $-5.7 \pm 0.8$ \\
\hline $\begin{array}{l}\text { GO- } \\
\text { PAM }\end{array}$ & $363 \pm 4$ & $2.9 \pm 0.2$ & 1.024 & $-5.8 \pm 0.7$ \\
\hline $\begin{array}{l}\text { GO- } \\
\text { PAA }\end{array}$ & $269 \pm 7$ & $2.6 \pm 0.2$ & 1.056 & $-2.6 \pm 0.7$ \\
\hline $\begin{array}{l}\text { GO- } \\
\text { PEG }\end{array}$ & $272 \pm 11$ & $4.1 \pm 0.3$ & 0.983 & $-4.6 \pm 1.1$ \\
\hline
\end{tabular}

${ }^{a}$ Measurements in water. ${ }^{b}$ AFM. ${ }^{c}$ Raman spectroscopy. ${ }^{d}$ Measurements in cell culture medium (DMEM $+10 \%$ serum).

Because of the attachment of PAM, PAA or PEG polymers on GO, the average layer thickness of PAM, PAA and PEG became greater than that of the pristine GO $(2.9,2.6$, and $4.1 \mathrm{~nm}, v s 1.1$ $\mathrm{nm}$ respectively; Figure $1 \mathrm{~b}$ and Table 1$)$. The AFM and transmission electron microscopy (TEM) images showed that all GO materials exhibited a single-layer sheet-like shape without obvious agglomeration (Figure $1 \mathrm{~b}, \mathrm{~d}$ ).

X-ray photoelectron spectroscopy (XPS) and Fourier transform infrared spectroscopy (FT-IR) were employed to assess the surface chemical properties of the GO materials. As shown in Figure 1e, XPS results showed the major characteristic peaks of $\mathrm{C} 1 \mathrm{~s}$ spectra including $\mathrm{C}-\mathrm{C} / \mathrm{C}=\mathrm{C}(284.5 \mathrm{eV})$, $\mathrm{C}-\mathrm{OH}(285.4 \mathrm{~V}), \mathrm{C}-\mathrm{N}(286.0 \mathrm{eV}), \mathrm{C}-\mathrm{O}(286.5 \mathrm{eV}), \mathrm{C}=\mathrm{O}$ 
(a)

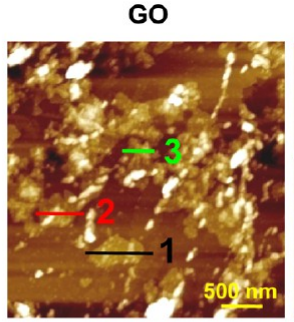

(b)

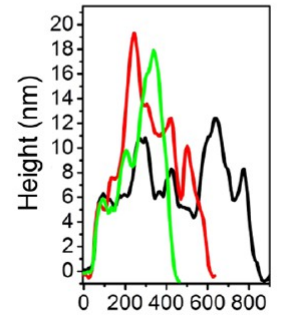

GO- $\mathrm{NH}_{2}$
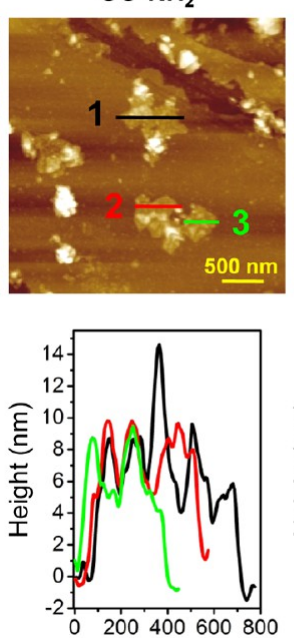

GO-PAM
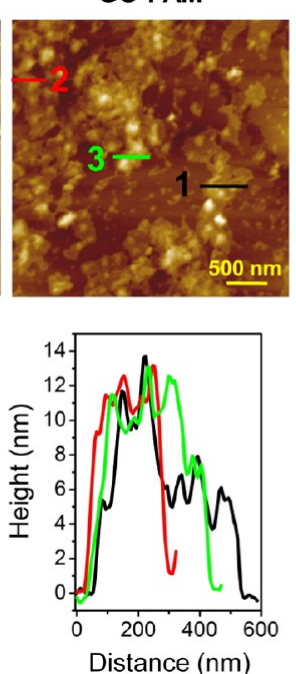

GO-PAA
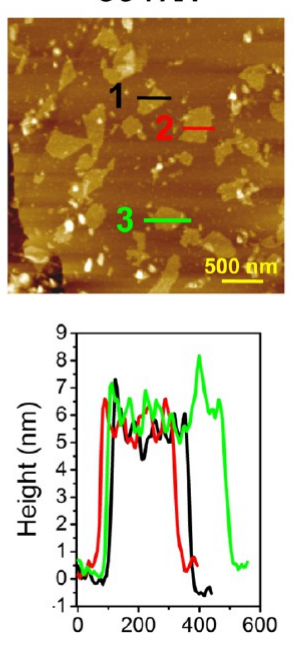

GO-PEG
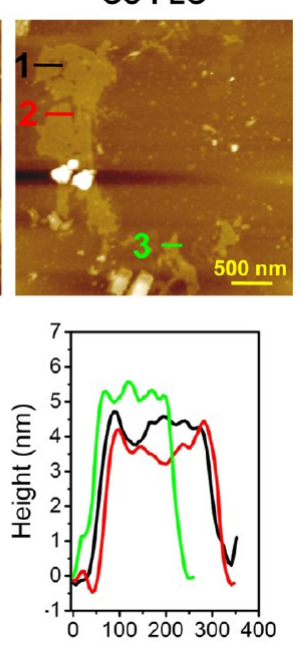

Figure 2. Morphological analysis of GO sheets after protein corona formation in cell culture medium through AFM. (a) AFM images and (b) height profiles of GO, GO- $\mathrm{NH}_{2}$, GO-PAM, GO-PAA and GO-PEG after 24 h-incubation in cell culture medium at $37^{\circ} \mathrm{C}$.

$(287.8 \mathrm{eV})$ and $\mathrm{O}=\mathrm{C}-\mathrm{C}(288.6 \mathrm{eV})$, representative of the changes of surface functional groups on GO sheets. For example, compared to pristine GO, the existence of nitrogen element in GO-NH $\mathrm{N}_{2}$, GO-PAM and GO-PEG was confirmed by the appearance of $\mathrm{C}-\mathrm{N}$ bonds (Figure 1e) and $\mathrm{N}$ 1s peak (Figure S1), suggesting that $\mathrm{NH}_{2}, \mathrm{PAM}$ and PEG had been successfully conjugated on GO sheets. The FT-IR spectra confirmed the characteristic vibrations of GO materials, as evidenced by a broad and intense peak of the $\mathrm{O}-\mathrm{H}$ group at $3421 \mathrm{~cm}^{-1}$, a $\mathrm{C}-\mathrm{O}$ stretching peak at $1106 \mathrm{~cm}^{-1}$, a $\mathrm{C}=\mathrm{O}$ stretching peak at $1720 \mathrm{~cm}^{-1}$ and a vibration of graphitic skeletal domains peak at $1625 \mathrm{~cm}^{-1}$ (Figure S2). The same Raman shift of $\mathrm{D}$ band $\left(\sim 1340 \mathrm{~cm}^{-1}\right)$ from a defect-induced breathing mode of $\mathrm{sp}^{2}$ rings and $\mathrm{G}$ band $\left(\sim 1600 \mathrm{~cm}^{-1}\right)$ from the vibration of $\mathrm{sp}^{2}$ bonded carbon atoms were observed for all GO materials, as reflected by Raman spectroscopy (Figure 1f), respectively. Similar $I_{\mathrm{D}} / I_{\mathrm{G}}$ values for all GO materials suggested that these materials had similar degree of disorder and defect content in their carbon structures. Figure S3 showed thermogravimetric analysis (TGA) curves of GO, GO- $\mathrm{NH}_{2}$, GO-PAM, GO-PAA and GO-PEG materials. The major mass loss of GO occurred approximately at $200{ }^{\circ} \mathrm{C}$ (Figure S3), presumably due to the pyrolysis of labile oxygen-contained functional groups to yield $\mathrm{CO}$ and $\mathrm{CO}_{2}$. For GO-NH removal of the thermally labile oxygen functional groups by chemical reduction increased its thermal stability, with slower weight loss in nitrogen atmosphere than GO (Figure S3). GOPAM, GO-PAA and GO-PEG showed a similar pattern of weight loss, occurring between 250 and $500{ }^{\circ} \mathrm{C}$ (Figure S3). These weight losses were accounted for by the decomposition and carbonization of PAM, PAA and PEG. Thus, it could be estimated that PAM, PAA and PEG approximately contained $25 \%$ graphene and $75 \%$ polymer.

The hydrodynamic sizes of all GO materials were within the range of $200-360 \mathrm{~nm}$ in water (Table 1 ). The $\zeta$-potential of all GO materials was mildly negative in cell culture medium, ranging from -2 to $-7 \mathrm{mV}$ (Table 1 ), due to the neutralizing effect by protein molecules. ${ }^{22}$ Regarding to their suspension stability and dispersity in water or cell culture medium, no obvious agglomeration was visualized post $24 \mathrm{~h}$ for all $\mathrm{GO}$ materials; however, $\mathrm{GO}$ and $\mathrm{GO}-\mathrm{NH}_{2}$ precipitated in phosphate buffer saline (PBS) that could be visually recognized and demonstrated by their particle size distribution curve measured using DLS (Figure S4). These data indicated that the protein corona indeed helped the nanoparticle dispersion by stabilizing GO sheets in salt solution. Furthermore, their morphological changes after protein corona formation in cell culture medium were examined by AFM (Figure 2). Compared to the morphology in water (Figure $1 \mathrm{~b}$ ), significant changes were found for GO and GO-PAM, suggesting their stronger interaction with proteins in cell culture medium than GO-NH GO-PAA and GO-PEG. For example, as shown in Figure 2a, GO sheets still remained in the single-layer sheet, whereas there were massive adsorbents adhered onto GO sheets that were likely formed by proteins. Conversely, less morphological changes were visualized for GO-PAA and GO-PEG, revealing less protein interactions in biological medium. These changes were also evidenced by the increase of layer thickness (Figure 2b) as follows, 9.2 $\pm 3.6,7.2 \pm 2.0,9.1 \pm 2.6,5.8 \pm 0.7$ and 4.5 $\pm 0.6 \mathrm{~nm}$ for GO, GO-NH $\mathrm{N}_{2}$, GO-PAM, GO-PAA and GOPEG, respectively. Relative to their layer thickness in water (Table 1), the increase after protein corona formation was calculated to be 8.1, 6.0, 6.2, 3.2, and $0.4 \mathrm{~nm}$ for GO, GO- $\mathrm{NH}_{2}$, GO-PAM, GO-PAA and GO-PEG, respectively. Moreover, based on the AFM analysis of the lateral size (Figure 2a), it appeared that proteins incurred a slight agglomeration of GO, GO-NH${ }_{2}$ and GO-PAM sheets into larger particles. Thereafter, we mainly focused on the study on the biocompatibility of GO with diverse surface properties, which was surely important for the real-life applications of GO materials, particularly in biomedical applications. So far, very few studies have been carried out to evaluate and compare the biosafety and biocompatibility of a variety of different GO derivatives together. Therefore, in this study we aimed to systematically tackle on this issue with differential GO derivatives using a wide spectrum of chemical, biochemical, in vitro and in vivo strategies.

Protein Corona Formation and Endocytosis of GO Nanoparticles by Macrophages. Because of the high surface free energy, nanoparticles will be rapidly coated by proteins in biological matrices (e.g., plasma), forming the so-called "protein corona" ${ }^{17}$ For example, the protein coronas of silica and 


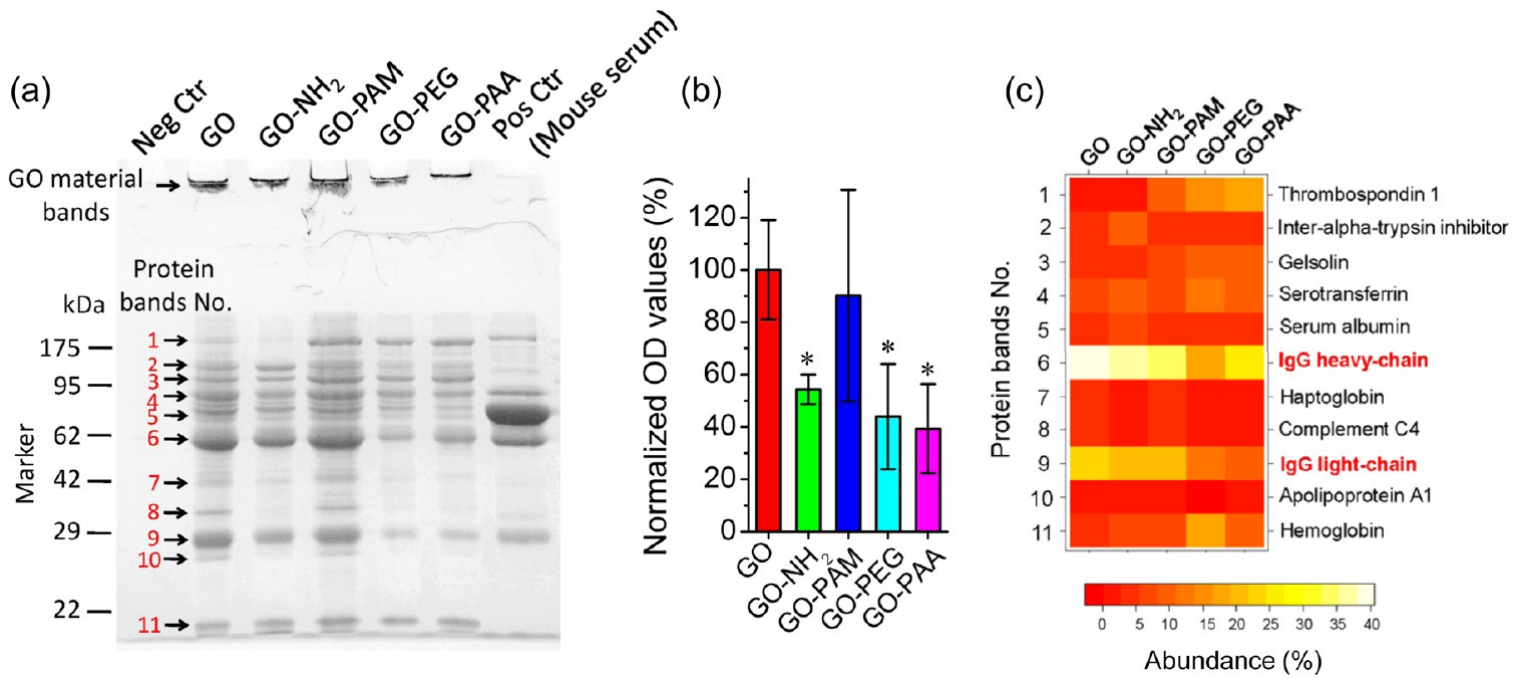

Figure 3. Protein corona analysis of GO, GO- $\mathrm{NH}_{2}$, GO-PAM, GO-PAA and GO-PEG formed in mouse serum at $37{ }^{\circ} \mathrm{C}$ for $1 \mathrm{~h}$. (a) Compositions of protein corona were analyzed by SDS-PAGE. The profile of protein bands in each lane represented the composition of protein coronas for GO materials. (b) Normalized OD values of each protein corona, reflecting the relative protein amount absorbed on GO sheets $(n=4)$. (c) Eleven high-abundant proteins (band \#1 to \#11 in (a)) were identified by mass spectrometry and quantitatively compared in the heat map $(n=4)$. Asterisk $(*)$ denotes $P<0.05$ compared to pristine GO.

(a)

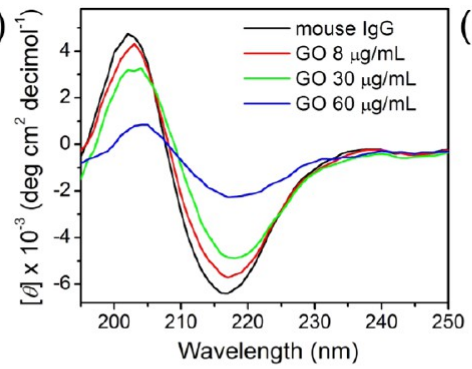

(d)

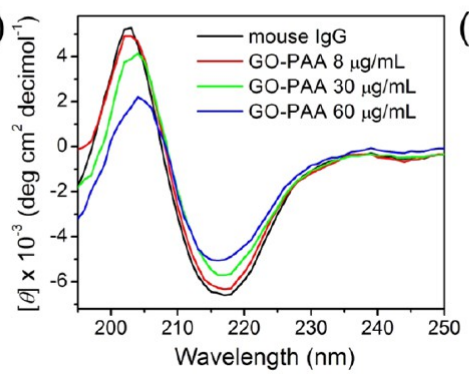

(b)

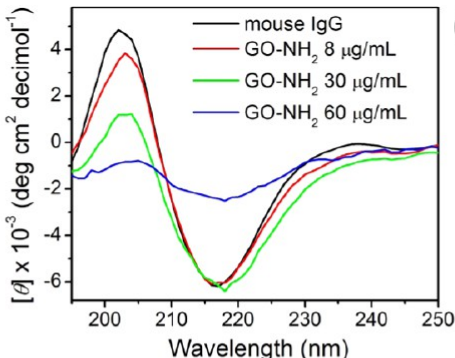

(e)

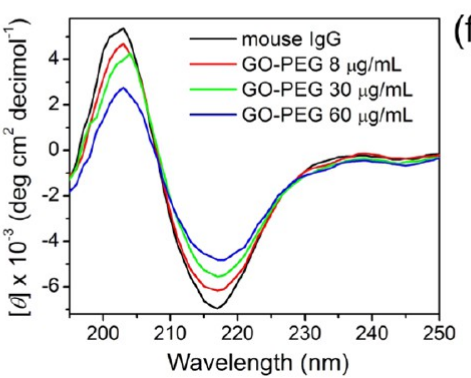

(c)

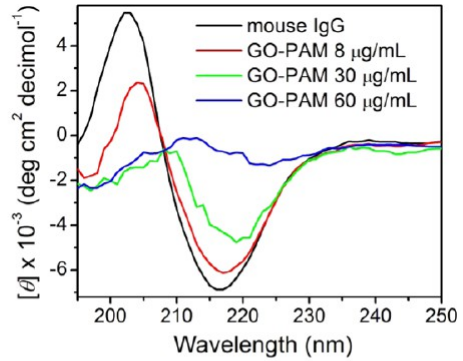

(f)

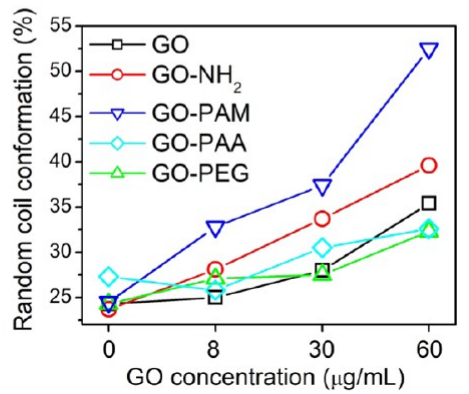

Figure 4. Secondary structural analysis of mouse IgG without or with (a) GO, (b) GO- $\mathrm{NH}_{2}$, (c) GO-PAM, (d) GO-PAA and (e) GO-PEG at 8, 30 , or $60 \mu \mathrm{g} / \mathrm{mL}$ measured by CD spectra. (f) Quantitative analysis of random-coil conformation in IgG protein without or with GO materials at concentrations as indicated.

polystyrene nanoparticles formed rapidly $(<30 \mathrm{~s})$ in plasma, comprising of approximately 300 different proteins. ${ }^{28}$ As important components of protein corona, opsonins (e.g., immunoglobulin $G$ and complement proteins) essentially enhance the reorganization of nanoparticles by immune cells and uptake by the reticuloendothelial system (RES). The identity of protein corona also fundamentally dictates the circulation, distribution, clearance and toxicity of nanoparticles. ${ }^{17}$ Ideally, therapeutic nanoparticles should be nontoxic and invisible to the immune system with longer systemic circulation and higher delivery to target sites. ${ }^{21}$ Thus, analysis of protein corona is crucial to understand and improve the biodistribution and biocompatibility of nanoparticles. ${ }^{17}$
For GO, the role of protein corona in determining their biological effects is still unclear. Herein, the protein coronas of GO, GO-NH$H_{2}$, GO-PAM, GO-PAA and GO-PEG formed in mouse serum were qualitatively and quantitatively analyzed based on the proteomic analytical strategy (Figure 3 and Table S1). ${ }^{28}$ As shown in Figure 3a, the profiles of protein bands represented the compositions of protein corona for each GO material. It could be discerned that the profiles for each GO material were quite different, indicating the protein corona on various GO sheets was distinct. Then, the protein coronas formed on different GO materials (at a GO concentration of 50 $\mu \mathrm{g} / \mathrm{mL}$ ) were analyzed quantitatively based on the optical density (OD) values. After normalization (Figure $3 \mathrm{~b}$ ), pristine GO (100\%) and GO-PAM (90.2\%) showed more protein 
adsorption than GO-NH $\mathrm{NH}_{2}$ (54.3\%), GO-PAA (39.3\%) and GOPEG (43.9\%), presumably due to their different surface charge (reflected by their $\zeta$-potential values in Table 1) and hydrophobicity. Furthermore, 11 abundant proteins were selected for comparison in the heat map (Figure $3 \mathrm{c}$ and Table S1). The relative amount of immunoglobulin G (including IgG heavy and light chains) in the protein coronas was much greater than other proteins, and a big difference was observed among pristine GO (62.2\%), GO- $\mathrm{NH}_{2}$ (58.3\%), GOPAM (52.3\%), GO-PAA (36.8\%) and GO-PEG (30.2\%). IgG is the most important antibody in the immune system, which plays a crucial role as opsonin in clearing invading pathogens. Its adsorption on GO sheets would promote the clearance of nanoparticles from circulation by agglomeration, ${ }^{29}$ and endocytosis by RES such as macrophages, resulting in less circulation time. $^{21}$ GO-PAA and GO-PEG had less IgG content in their protein corona (ca. 30-40\%) than that (ca. 50-70\%) of $\mathrm{GO}, \mathrm{GO}-\mathrm{NH}_{2}$ and GO-PAM, implying they would be less visible to sentinel cells such as macrophages. To test our hypothesis, the interactions between mouse IgG and GO materials were identified using circular dichroism (CD) spectra. In Figure 4, the CD spectra showed a significant alteration of the secondary structure (namely $\alpha$-helices, $\beta$-sheets, $\beta$-turn and random-coil) of $\operatorname{IgG}$ upon interaction with $\mathrm{GO}$ at 8,30 , and 60 $\mu \mathrm{g} / \mathrm{mL}$. By contrast, GO-PAA and GO-PEG elicited less impact on the secondary structure of IgG than GO, GO- $\mathrm{NH}_{2}$ and GOPAM (Figure 4). As the concentration of GO, GO- $\mathrm{NH}_{2}$ or GOPAM increased from 8 to $60 \mu \mathrm{g} / \mathrm{mL}, \operatorname{IgG}$ gradually lost its typical secondary structure (i.e., $\alpha$-helices, $\beta$-sheets and $\beta$-turn), as evidenced by the quantitative analysis of their random-coil conformation (Figure 4f). These observations for the secondary structure changes of IgG suggested that GO-PAA and GO-PEG interacted with IgG more mildly than the other three GOs, and these data also underlined the potential mechanism by which GO-PAA and GO-PEG adsorbed less IgG content in their coronas. Moreover, the role of IgG within the protein corona in phagocytosis was investigated with J774.A1 macrophages. Compared to bovine serum albumin (BSA) as a negative control (Figure 5), the presence of mouse IgG remarkably
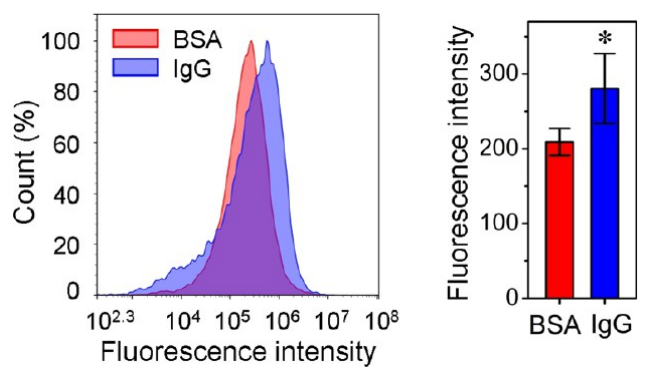

Figure 5. Quantitative analysis of the adhesion and uptake of GO by J774A.1 cells with addition of BSA or mouse IgG in serum-free DMEM medium at $4 \mu \mathrm{g} / \mathrm{mL}$ after $24 \mathrm{~h}$-exposure using flow cytometry. Quantified data were shown in the left panel $(n=4)$. Asterisk (*) denotes $P<0.05$ compared to the BSA control.

facilitated the recognition and phagocytosis of GO sheets by macrophages in serum-free cell culture medium, and the quantified data showed approximately $34 \%$ increase of intracellular FITC fluorescence intensity, suggesting enhanced uptake of GO by IgG relative to BSA $(P<0.05)$. These results collectively demonstrated that IgG within the protein corona of GO could be readily recognized by immune cells such as macrophages, and this recognization critically dictated the biocompatibility and the biological behaviors of GO. However, it should also be kept in mind that other proteins (such as complement $\mathrm{C} 4$ or serotransferrin) might also play similar roles via their specific ligand-receptor interactions in affecting circulation time, biocompatibility and toxicity of GO materials. Moreover, potential ligand-receptor interactions through other unknown proteins may also explain the different biological effects of GO-PAA and GO-PEG. These unanswered questions demand further detailed investigation.

We thereafter performed in vitro and in vivo experiments to test the toxicity of the GO materials. A phagocyte cell line macrophage J774.A1 was selected for in vitro study. First, the cytotoxicity of pristine GO were determined by alamar blue $(\mathrm{AB})$ assay and cell counting kit 8 (CCK-8) assay (Figure S5a,b). No significant toxicity was observed in J774A.1 cells when the concentration of pristine GO was below $10 \mu \mathrm{g} / \mathrm{mL}$. The effects of pristine GO at 1, 4, 10, 50, 100, or $200 \mu \mathrm{g} / \mathrm{mL}$ on proliferation of cells was further evaluated by cell number counting (Figure S5c). In accordance with the results of $A B$ assay and CCK-8 assay, the cytotoxicity of GO was dosedependent, showing significant toxicity above $10 \mu \mathrm{g} / \mathrm{mL}$. Furthermore, the cytotoxicity of all GO materials was determined with the CCK- 8 assay at $1,2,4,10,20,50$, or $100 \mu \mathrm{g} / \mathrm{mL}$. As shown in Figure 6, the results indicted that only

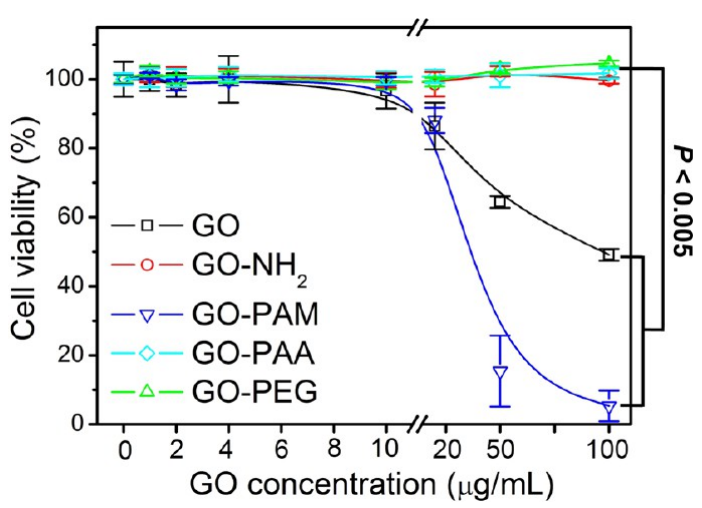

Figure 6. Cell viability of J774A.1 cells exposed to GO, GO- $\mathrm{NH}_{2}$ GO-PAM, GO-PAA or GO-PEG at $1,2,4,10,20,50$, and $100 \mu \mathrm{g} /$ $\mathrm{mL}$ for $24 \mathrm{~h}(n=5)$. Cell viability was evaluated with the CCK-8 assay method.

GO and GO-PAM were toxic to J774.A1 cells at concentrations greater than $10 \mu \mathrm{g} / \mathrm{mL}$, whereas the other $\mathrm{GO}$ materials displayed no toxicity to cells. Thus, sublethal concentrations $(<10 \mu \mathrm{g} / \mathrm{mL})$ were used in the following experiments for all GO materials.

Previous studies suggested that protein corona could greatly reduce the cytotoxicity of carbon nanoparticles (e.g., GO and carbon nanotube) in Hela, THP-1 and A549 cells. ${ }^{30-33}$ Consistent with previous reports, as shown in Figure $\mathrm{S} 5 \mathrm{~d}$, the number of GO-treated cell was $52.5 \%$ lower than untreated cells without the addition of serum, and the addition of serum almost abolished the toxicity of pristine GO to J774.A1 cells at a sublethal concentration of $4 \mu \mathrm{g} / \mathrm{mL}$. Interestingly, treatment with other $\mathrm{GO}$ derivatives $\left(\mathrm{GO}-\mathrm{NH}_{2}, \mathrm{GO}-\mathrm{PAM}, \mathrm{GO}-\mathrm{PAA}\right.$ and GO-PEG) resulted in significantly lower cytotoxicity than pristine GO at this concentration. In serum-containing cell culture mediums, the cell numbers for $\mathrm{GO}, \mathrm{GO}-\mathrm{NH}_{2}, \mathrm{GO}-\mathrm{PAA}$ and GO-PEG could reach $>90 \%$ of the untreated group, whereas it was only $\sim 80 \%$ for GO-PAM, indicating it was more 
(a)

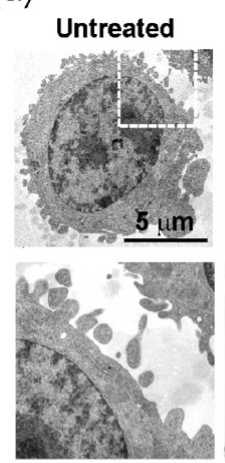

GO-PAM
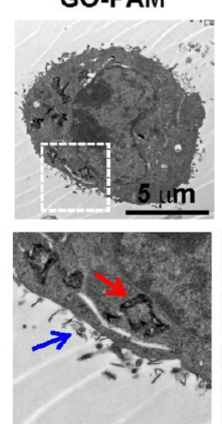

GO

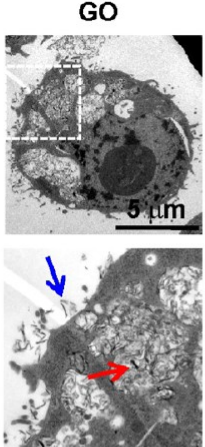

GO-PAA
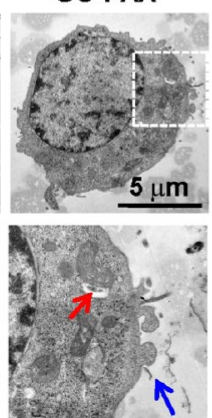

GO-NH

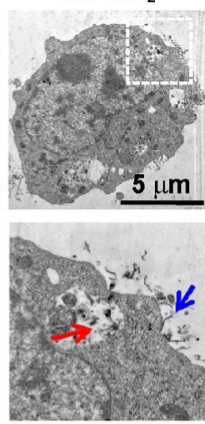

GO-PEG

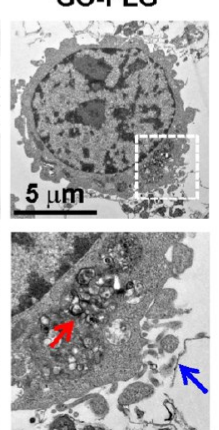

(b)
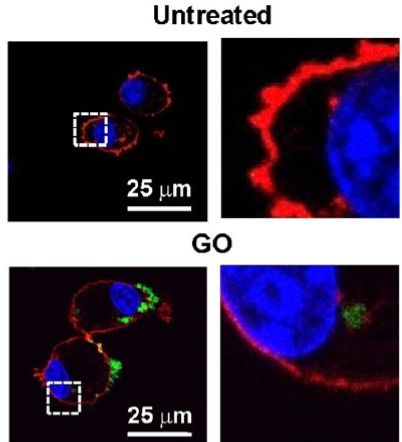

(c)

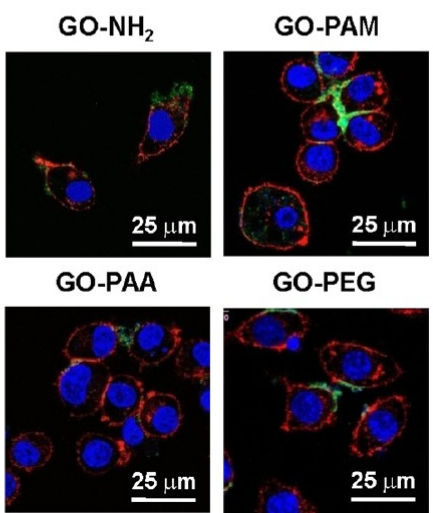

Figure 7. Cellular localization of GO sheets in J774A.1 cells visualized by high-resolution TEM (original magnification, $\times 10000$ ) and laser scanning confocal microscopy (original magnification, $\times 63$ ). (a) TEM images of cells treated with GO, GO-NH 2 , GO-PAM, GO-PAA or GOPEG at $4 \mu \mathrm{g} / \mathrm{mL}$ for $24 \mathrm{~h}$. Locations of GO on membrane (blue arrows) and inside phagosomes (red arrows) were denoted in the enlarged images (lower) from the dash line squares. Cells were treated with FITC-BSA labeled (b) GO or (c) GO derivatives (in green) at $4 \mu \mathrm{g} / \mathrm{mL}$ for $24 \mathrm{~h}$. Cells were then subjected to cytoskeleton staining with Rhodamine-phalloidin (in red) and nuclear staining with $4^{\prime}, 6$-diamidino-2phenylindole dihydrochloride (DAPI, in blue). Enlarged images (on the right) from the line squares indicate the enlarged thinner and flatter plasma membrane following GO treatment, compared with untreated cell.

cytotoxic than the others. The adhesion and phagocytosis of GO by macrophages were inspected by high-resolution TEM and laser scanning confocal microscopy. GO sheets were located in the cytosol (readily seen in membrane bound structures, namely phagosomes) and on the plasma membrane as well (Figure 7). Importantly, there was a significant difference for cells treated with $\mathrm{GO}$ derivatives in comparison to pristine GO. For cells exposed to pristine GO, GO-NH GO-PAM, GO-PAA or GO-PEG, intracellular phagosomes containing GO sheets could be readily found (indicted by red arrows in Figure 7a). In support of these observations, laser scanning confocal microscopy images also showed that GO sheets mainly adhered onto cell membrane in GO-treated cells (Figure 7b,c). Meanwhile, more GO sheets were identified on plasma membrane for GO and GO-PAM treated cells (denoted by blue arrows in Figure 7a) by TEM. Moreover, the uptake of fluorescein isothiocyanate-bovine serum albumin (FITC-BSA)labeled GO by J774.A1 cells were quantified using flow cytometry (Figure S6), showing an order of cellular association and uptake as follows, GO > GO-PAM > GO-PEG > GO-NH and GO-PAA. These data together demonstrated that pristine GO could be easily recognized and phagocytosed by macrophages, and surface modifications considerably reduced the recognition by macrophages in varying degrees. These results were in agreement with the findings of their differential protein coronas (Figure 3), as described above.

Interactions between GO Nanoparticles and Cell Membrane. Regarding the molecular mechanisms underlying GO association with plasma membrane and GO-induced toxicity to cells (particularly macrophages), our own work together with others' demonstrated that the interaction between GO sheets and plasma membrane determined GO's adhesion toward macrophages and its uptake by macrophages. ${ }^{3,9,35,36}$ Moreover, we recently demonstrated a sizedependent interaction between GO and macrophagic plasma membrane, which accounted for the M1 induction of macrophages and pro-inflammatory responses of GO in vitro and in vivo. ${ }^{36}$ Cell membrane is an important barrier to maintain the balance of intracellular environment, and impairment of its integrity could result in cellular dysfunctions and even cell death. Cell membrane integrity is an ideal parameter to reflect the biocompatibility of nanomaterials. Thus, understanding the interactions between cell membrane and GO materials is crucial for the interpretation of their different biological effects. ${ }^{3,34}$ GO sheets would adhere and wrap around cell membrane, insert in lipid bilayer or be internalized into cell as the consequence of interactions at the cellular level. Consequently, physical and/or biological damages of cell membrane might happen. A recent study revealed that the protein corona played a crucial role in mitigating this interaction through reducing cell membrane penetration. ${ }^{33}$ Our recent findings also demonstrated that $\mathrm{GO}$ could also trigger the programmed necrosis on macrophages through the interaction with membrane Toll-like receptors and lateral size played a crucial role in affecting this interaction. ${ }^{35,36}$ To date, the interaction with macrophagic membrane of GO with different surface modifications has not been thoroughly investigated. Thus, we afterward embarked on the influence 
(a)

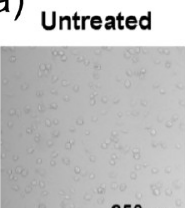

$250 \mu \mathrm{m}$

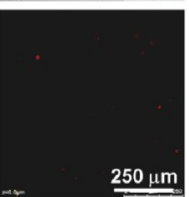

GO-PAM

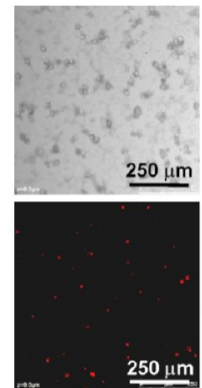

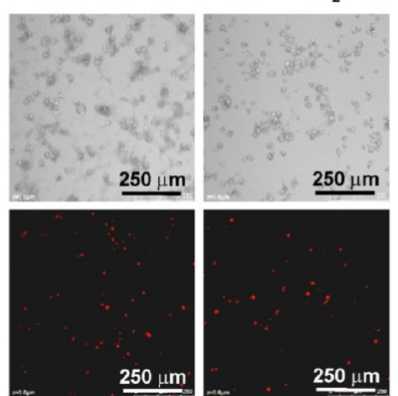

GO-PAA

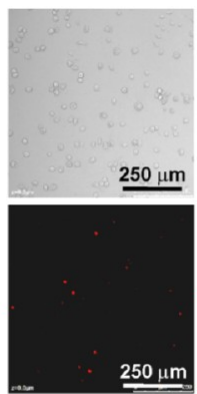

GO-NH

GO-PEG

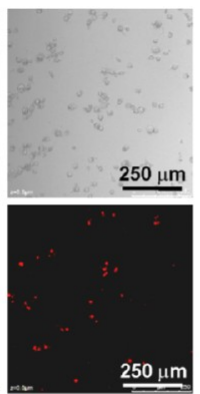

(b)

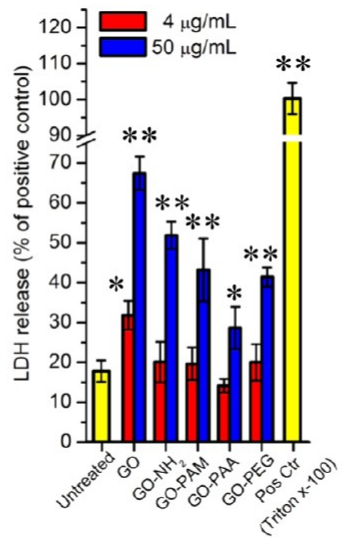

(c)

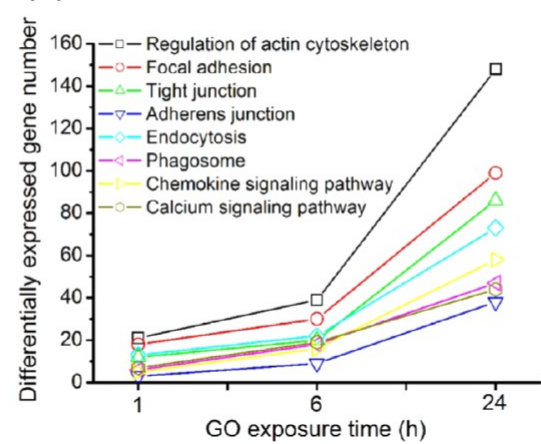

(d)

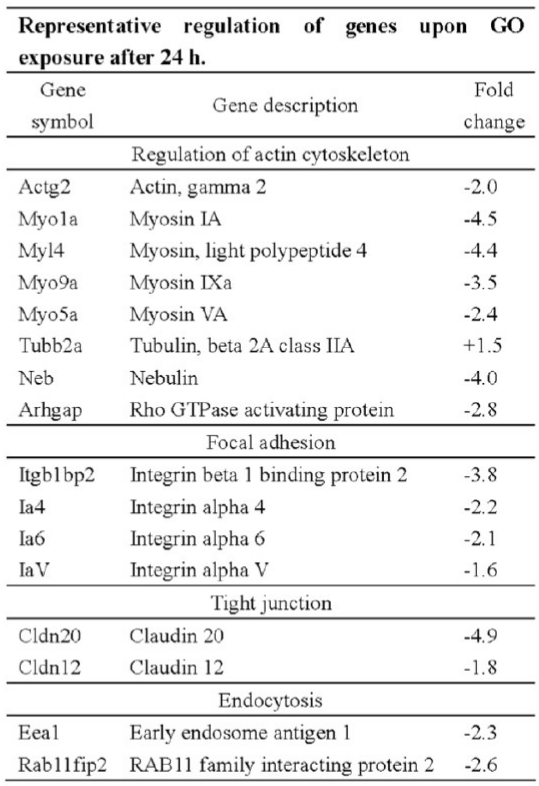

Figure 8. Cell membrane damages induced by GO materials. (a) Phase-contrast images and confocal microscopy images with PI staining (in red) showing the alteration of membrane permeability of J774A.1 cells after treatment with GO materials at $4 \mu \mathrm{g} / \mathrm{mL}$ for $24 \mathrm{~h}$ (original magnification, $\times 10$ ). For untreated, GO, GO- $\mathrm{NH}_{2}$, GO-PAM, GO-PAA or GO-PEG group, the percentage of PI-positive cells is 3, 35, 12, 25, 9 and $23 \%$, respectively $(n=3)$. (b) LDH release from J774A.1 cells post treatment with GO materials at 4 or $50 \mu \mathrm{g} / \mathrm{mL}$ for $24 \mathrm{~h}(n=5)$. (c) Analysis of cell membrane-related gene expression in J774A.1 cells at $4 \mu \mathrm{g} / \mathrm{mL}$ for 1,6 , and $24 \mathrm{~h}$ following GO exposure by RNA-Seq transcriptome analysis. (d) Representative differentially expressed cell membrane-related genes with functional descriptions in J774A.1 cells at $4 \mu \mathrm{g} / \mathrm{mL}$ for $24 \mathrm{~h}$ following GO exposure. A $\log 2$ fold change is used to describe the gene expression of GO-treated cells compared to untreated cells. Asterisk $(*)$ and $(* *)$ denotes $P<0.05$ and $P<0.005$ compared to untreated cells, respectively.

of GO surface modifications on the interaction with the membrane of macrophages.

To define the interaction between GO and cell membrane, various membrane parameters including morphology, permeability, fluidity and ion channels were closely examined. As shown in Figure 7 and 8 and Figure S7-S10, cell membrane damage was largely dose-dependent, in spite of being less extensive than previous results from other groups. ${ }^{32,37-39} \mathrm{GO}$ exposure induced significant morphological changes of J774A.1 cells with thinner and flatter plasma membrane (Figure $7 \mathrm{~b}$ ). Along with these morphological changes, the permeability of cell membrane became higher, as evidenced by propidium iodide (PI) staining and lactate dehydrogenase (LDH) release assay (Figure 8a,b and Figure S7 and S8). This damage could be further verified by approximately $30 \%$ increase of $\mathrm{Ca}^{2+}$ influx in J774A.1 cells in response to $4 \mu \mathrm{g} / \mathrm{mL} \mathrm{GO}$, in parallel to the injuries of the structures of lipid bilayer and the $\mathrm{Ca}^{2+}$ channel (Figure S9). Meanwhile, the fluidity of cell membrane was found to decrease with increasing GO concentration, indicating that the lipid bilayer was perturbed by GO sheets (Figure S10). Our recent studies uncovered pronounced alterations to cellular morphology (including surface protrusions, cellular adhesion and spreading), suggesting remarkably undermined assembly and organization of cytoskeleton. ${ }^{35,36}$ To gain more insights into the molecular mechanisms responsible for GO-induced damages to cell membrane, genome-wide gene expression was determined at 1,6 , and $24 \mathrm{~h}$ post GO exposure by RNA-Seq transcriptome analysis. As shown in Figure 8c, significant changes in gene expression manifested that GO seriously affected cellular physiology and functions through genetic regulations, and this effect was closely related to the exposure time. Functional analysis of the differentially expressed genes showed that a number of these genes was responsible for the structure and functions of cell membrane, such as regulation of actin cytoskeleton, focal adhesion and endocytosis (Figure 8d). For example, focal adhesion-associated 99 genes were found to be differentially expressed including 18 up-regulated and 81 down-regulated genes at $24 \mathrm{~h}$ post GO exposure. As focal adhesion serves as the mechanical linkages to the extracellular matrix, the abnormal expression of its related genes (e.g., integrin) would lead to the damage of cell membrane and affect the cellular behavior (e.g., cell migration). ${ }^{40-42}$ To this end, we could conclude that GO treatment significantly altered the expression of membrane/cytoskeleton-related genes, and deregulation of these genes greatly contributed to GO-elicited damages to cell membrane.

We also compared the impact of GO- $\mathrm{NH}_{2}$, GO-PAM, GOPAA and GO-PEG on cell morphology, membrane permeability, fluidity and ion channels. As shown in Figure S7b, pristine $\mathrm{GO}, \mathrm{GO}-\mathrm{NH}_{2}$ and GO-PAM induced pronounced morphological alterations of macrophages with significant cellular collapses and resulting stretching of cellular bodies. While the results of membrane permeability, fluidity, $\mathrm{Ca}^{2+}$ flux and $\mathrm{LDH}$ release showed that GO- $\mathrm{NH}_{2}$ and GO-PAM at $4 \mu \mathrm{g} /$ $\mathrm{mL}$ also caused significant damage to cell membrane, similar to pristine GO. However, GO-PEG and GO-PAA had less 
(a)

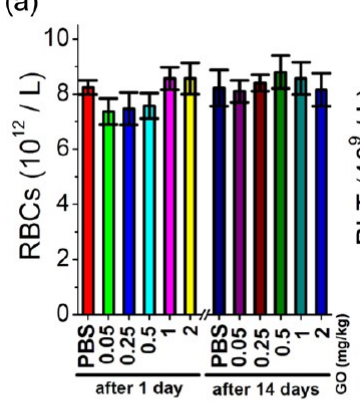

(d)

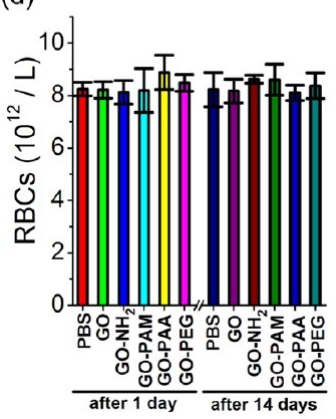

(b)

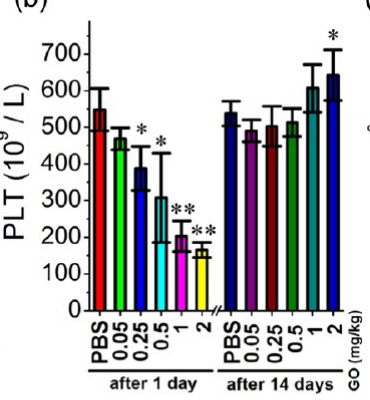

(e)

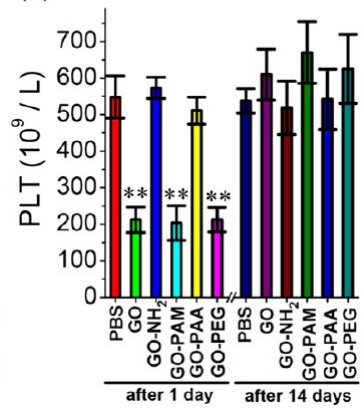

(c)

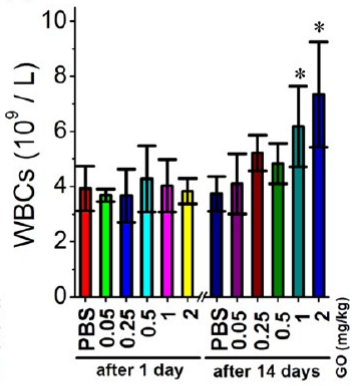

(f)

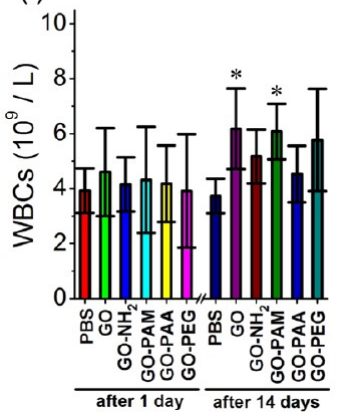

Figure 9. Hematological analysis of peripheral blood for mice administrated with GO materials. (a) RBCs, (b) platelet and (c) WBCs counts for mice administrated with different concentrations of pristine GO for 1 day or 14 days. (d) RBC, (e) platelet and (f) WBC counts for mice administrated with pristine GO, GO- $\mathrm{NH}_{2}$, GO-PAM, GO-PAA or GO-PEG at $1 \mathrm{mg} / \mathrm{kg}$ for 1 day or 14 days. There were 10 animals in each group $(n=10)$. Asterisk $(*)$ and $(* *)$ denotes $P<0.05$ and $P<0.005$ compared to PBS-treated mice.

disruption to cell membrane (Figure 8a,b and Figure S9 and S10). To clarify the difference, in addition to $4 \mu \mathrm{g} / \mathrm{mL}, \mathrm{LDH}$ release was also determined at $50 \mu \mathrm{g} / \mathrm{mL}$. As shown in Figure $8 \mathrm{~b}$, similar results were demonstrated. Regarding intracellular $\mathrm{Ca}^{2+}$ flux results, GO and GO-PAM caused significant $\mathrm{Ca}^{2+}$ influx, whereas $\mathrm{GO}-\mathrm{NH}_{2}$ incurred $\mathrm{Ca}^{2+}$ efflux (Figure S9), presumably due to distinct interaction, which warrants further investigation. Overall, membrane impairments were ameliorated after surface modifications: GO > GO-PAM and GO$\mathrm{NH}_{2}>$ GO-PEG and GO-PAA. Compared to other GO materials, the damages of cell membrane by GO-PAA were significantly lower, indicating that the PAA modification was compatible to cell membrane. These findings correlated well with the characterization data of their protein coronas (Figure 3); however, the differential interactions of GO-PEG and GOPAA with macrophages and plasma membrane may also be explained by ligand-receptor interactions through other uninvestigated proteins. Taken together, these results suggested that less protein adsorption (e.g., opsonins) on GO-PEG and GO-PAA sheets led to reduced interactions with cell membrane proteins and lipid bilayer than the other GO materials, resulting in less endocytosis and improved biocompatibility.

In Vivo Biocompatibility of GO Materials in Mice. To validate the in vitro findings, the in vivo biocompatibility of GO materials was determined. The biocompatibility of GO materials was assessed in mice through intratail vein administration. First, the dose-dependent effects of pristine GO were closely examined in mice at $0.05,0.25,0.5,1,2,5,10$, or $20 \mathrm{mg} / \mathrm{kg}$. After GO administration, the survival rate of male $\mathrm{BALB} / \mathrm{c}$ mice was $100,80,60,20$ and $0 \%$ for the concentrations at $0.05,1,5,10$, and $20 \mathrm{mg} / \mathrm{kg}$, respectively (Figure S11a). All deaths occurred on the first day after treatment (Figure S11a), suggesting that the in vivo lethal effect of GO was acute. Moreover, this toxicity could also be evidenced by the loss of body weight (Figure S11b). For the survived mice, the increase of body weight was less than that of untreated mice, and this difference became more significant at higher GO concentrations (Figure S11b, $P<0.05$ ). Following, the toxicity of the other GO derivatives was examined at $1 \mathrm{mg} /$ $\mathrm{kg}$. The survival rate of GO, GO-NH, $\mathrm{NH}_{2}$ GO-PAM, GO-PAA and GO-PEG was 80, 100, 90, 100 and 100\%, respectively (Figure S11c). This finding indicated that $-\mathrm{NH}_{2},-\mathrm{PAA}$ and -PEG modifications could greatly reduce the gross toxicity of GO in mice. For pristine GO, GO-NH, $\mathrm{NH}_{2}$ GO-PAM, GO-PAA and GOPEG administrated mice at $1 \mathrm{mg} / \mathrm{kg}$ body weight, GO-PAMtreated mice showed the greatest growth retardation in comparison to mice upon other GO materials (Figure S11d, $P<0.05)$. In addition to GO-PAM, pristine GO also inhibited weight increase in mice (Figure $S 11 \mathrm{~d}, P<0.05$ ). The ranking of suppression in body weight increase is GO-PAM > GO > GO$\mathrm{NH}_{2}$ and GO-PEG > GO-PAA, and $\mathrm{NH}_{2}-$, PEG- and PAAmodifications revealed lower gross toxicity than GO.

Among the five $\mathrm{GO}$ materials, the in vivo toxicity of $\mathrm{NH}_{2}$ and PEG- modified graphene or GO, has been evaluated previously. ${ }^{11,43-45}$ Pristine GO could cause significant pathological changes including inflammatory cell infiltration, pulmonary edema and granuloma formation at high doses. $^{43,44}$ Although $\mathrm{NH}_{2-}$ and PEG- modifications were reported to be more biocompatible than pristine graphene or $\mathrm{GO},{ }^{11,45}$ there is no detailed investigation on their in vivo toxicity. Therefore, in vivo toxicity induced by these GO materials was thoroughly assessed. First, the biological effects on blood cells in peripheral circulation were tested (Figure 9 and Figure S12). GO materials caused little change to red blood cells (RBCs) after a short or long time treatment (Figure 9a,d), similar to the previous report. ${ }^{43}$ However, significant platelet (PLT) depletion in peripheral blood occurred after pristine GO administration for 1 day in a clear dose-dependent manner (Figure 9b, $P<0.05$ ). Meanwhile, other hematological indexes remained similar after treatment for pristine GO. Platelet is an 
(a)

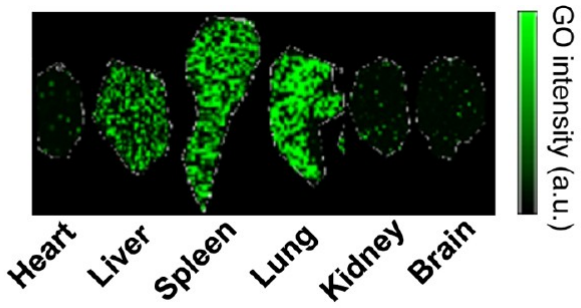

(b)

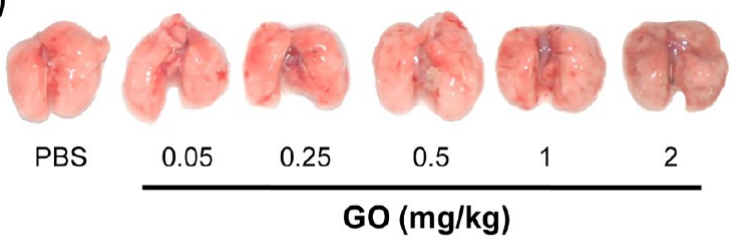

(c) Lung

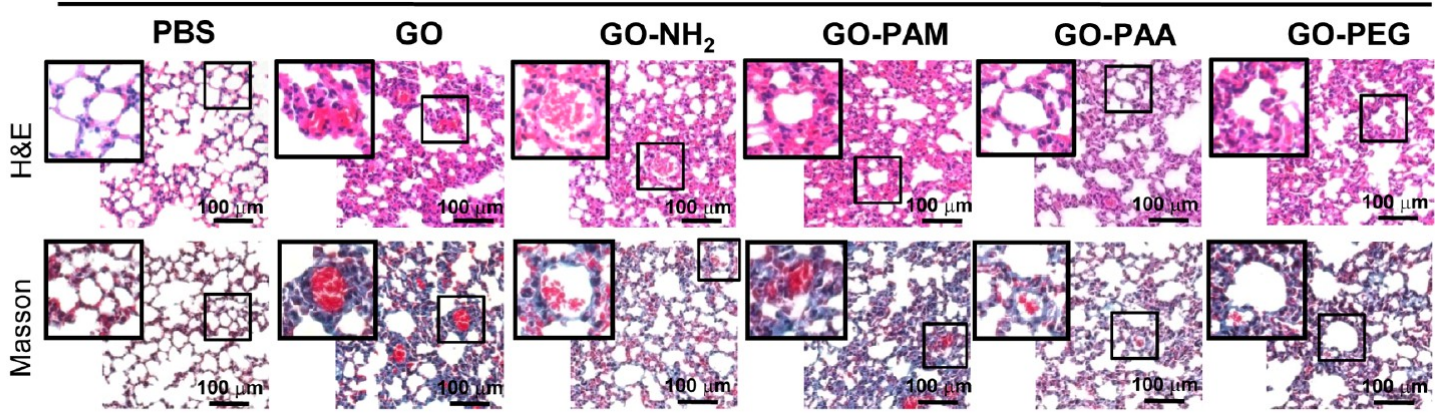

(d)

Liver

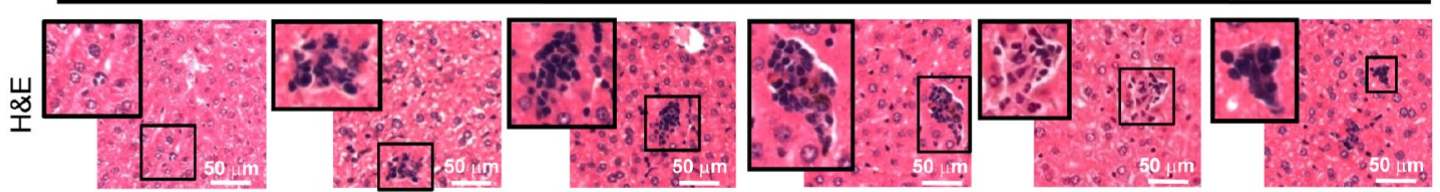

(e)

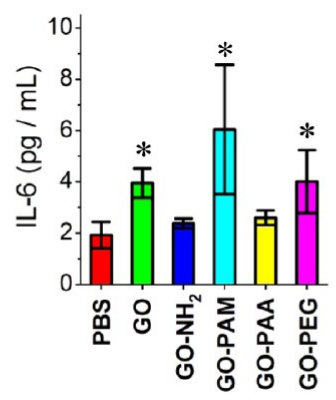

(f)

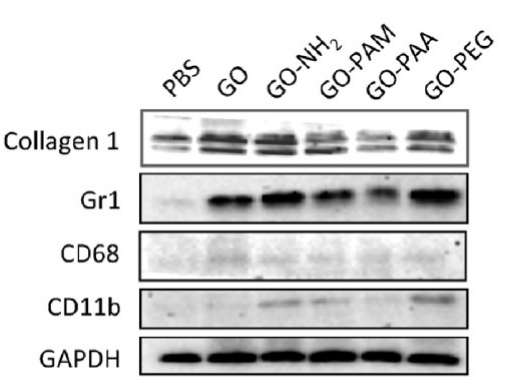

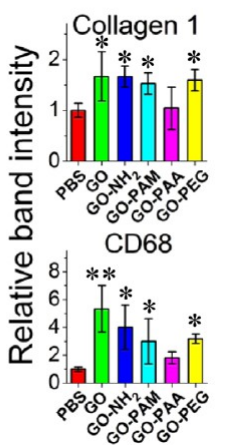

Figure 10. Toxicity assessments in mice. (a) LDI IMS image indicates tissue distribution of GO in mice administrated with pristine GO (2 $\mathrm{mg} / \mathrm{kg}$ body weight) after 1 day. (b) Images of lungs from mice following administration of pristine GO at $0.05,0.25,0.5,1$, and $2 \mathrm{mg} / \mathrm{kg}$ body weight for 1 day. Histological examination of (c) lungs with H\&E and Masson's trichrome staining and (d) livers with H\&E staining from mice post treatment of $1 \mathrm{mg} / \mathrm{kg} \mathrm{GO}$ materials for 14 days (original magnification, $\times 100$ ). Enlarged images from the line squares denote the enlarged pulmonary alveoli. Dark spots represent GO-cell complexes in livers (original magnification, $\times 200$ ). For Masson's trichrome staining, blue color indicates collagen in lung. (e) Levels of pro-inflammatory cytokines IL-6 in sera from mice administrated with a single dose of GO materials at $1 \mathrm{mg} / \mathrm{kg}$ body weight for 1 day $(n=5)$. (f) Determination of protein markers of collagen 1 , Gr1, CD68 and CD11b through Western blot analysis in lungs from mice post GO administration at $1 \mathrm{mg} / \mathrm{kg}$ body weight for 14 days. Quantified data were shown in the right panel $(n=4)$. Asterisk $(*)$ and $(* *)$ denotes $P<0.05$ and $P<0.005$ compared to PBS-treated mice.

important component to form clotting and to modulate immune response to invading pathogens and particulate matters. ${ }^{46}$ A previous study suggested that platelet activation could be directly triggered through its surface receptors by GO, and then platelet-rich thrombi would occlude lung vessels. ${ }^{11}$ The decrease of platelet number in peripheral blood implied a direct activation by GO. The platelet numbers recovered to the comparable level to untreated mice after 2 weeks; however, the counts of white blood cells (WBCs) including neutrophils and lymphocyte were greatly increased by $79 \%$ for mice treated with GO at that time point (Figure 9c and S12, $P<0.05$ ), suggesting robust pro-inflammatory responses induced by GO after the long-term exposure. On the basis of these findings, we postulated that platelet depletion was a good indicator for in vivo biocompatibility of GO in a short exposure period, whereas the extent of pro-inflammatory responses could determine its long-term detrimental effects. Thus, other GO derivatives were subjected to the evaluation of hematological parameters. As shown in Figure 9e, pristine GO, GO-PAM and GO-PEG depleted platelets in peripheral blood after 1 day treatment, whereas GO- $\mathrm{NH}_{2}$ and GO-PAA did not. This observation was in accordance with a previous report, where $\mathrm{NH}_{2}$-modified graphene exhibited no effect on platelets, compared to GO. ${ }^{11}$ Analogous to pristine GO, the platelet number became similar to untreated mice after 2 weeks (Figure 9e). Furthermore, in agreement with the above results, GO-PAA did not induce increase of WBCs after long-term exposure (Figure 9f). 
Together, GO-PAA showed the highest biocompatibility in blood, compared to GO-PEG and other GO materials.

To further shed light on the in vivo biocompatibility of GO materials, their toxicity to major organs was examined. Figure 10a showed that lung, liver and spleen were the major organs for GO accumulation, as evidenced by laser desorption/ ionization mass spectrometry (LDI IMS) mapping, a new method developed recently. ${ }^{47}$ As the GO concentration increased, the color of lungs became darker, a sign of enhanced GO accumulation (Figure 10b), analogous to a previous finding. ${ }^{44}$ Histological examination of lung, liver and spleen was performed through hematoxylin and eosin (H\&E) and Masson's trichrome staining (Figure S13 and S14). Pristine GO induced extensive lung injuries, as manifested by inflammatory cell infiltration, alveolar wall thickening and increased collagen in bronchioles, especially at higher concentrations (Figure S13). Meanwhile, significant occlusion of lung blood vessels with platelet thrombi was observed at high concentrations of 1 and $2 \mathrm{mg} / \mathrm{kg}$ body weight (Figure S13, as indicated by arrows). Fibrosis and inflammation were further verified by the increased levels of protein markers: collagen 1 indicative of fibrosis, Gr1 for neutrophils, CD68 representative of macrophages and $\mathrm{CD} 11 \mathrm{~b}$ for myeloid cells in lungs from pristine GO-treated mice (Figure S15). Moreover, the concentrations of interleukin-6 (IL-6) and tumor necrosis factor (TNF- $\alpha$ ) were also greatly elevated in sera from pristine GO-treated mice (indicative of acute inflammatory responses), especially at higher concentrations and after 1 day treatment (Figure S16a,b). Fibrosis could be further identified by a higher level of collagen 1 in lungs from mice after GO exposure at 1 or $2 \mathrm{mg} / \mathrm{kg}$ body weight, as characterized by enhanced blue color of lung tissues post 1 and 14 day treatment after Masson's trichrome staining (Figure 10c and Figure S13b and S15). Moreover, the elevation of Gr1, CD68 and CD11b levels indicated that inflammatory cells including neutrophils, macrophages and myeloid cells were recruited to lungs after GO exposure for 14 days (Figure S15). Although no significant pathological alterations were observed in liver, dark spots were identified after 14 days (Figure S14, denoted by arrows), indicative of the formation of GO-cell complex, as previously described. $^{48}$ In agreement with this finding, there were enhanced enzymatic activities for aspartate transaminase (AST) and alanine transaminase (ALT) in sera from mice post GO treatment, especially after an acute treatment, suggesting potential liver damage (Figure S16c,d). By contrast, no pathological damages were observed in spleen (data not shown). Collectively, pristine GO prominently elicited impairments in lung and liver after intratail vein injection, and the toxicity closely relied on the dosage and exposure time.

We also studied the in vivo toxicity of GO derivatives. As shown in Figure 10, compared to untreated mice, all GO materials induced injures to liver and lung after 14-day treatment, to a distinct extent. The most pronounced injuries were observed in GO- and GO-PAM-treated mice, as evidenced by the dramatic histological alterations in $\mathrm{H} \& \mathrm{E}$ and Masson's trichrome staining (Figure 10c,d). By contrast, GO-PAAtreated mice showed the least impairment in liver and lung, compared to other GO materials including pristine GO-, GO$\mathrm{NH}_{2-}$, GO-PAM and GO-PEG-treated mice (Figure 10c,d). The differences for the in vivo toxicity were further supported by the distinct changes of ALT, AST, IL-6, collagen 1 content (representative of fibrosis) and recruitment of inflammatory cells (Figure 10e,f and Figure S17, $P<0.05$ ). Taken together, these results showed the important role of chemical modifications on GO surface in causing in vivo toxicity.

\section{CONCLUSIONS}

The current study further expanded our understanding of the molecular mechanisms responsible for GO-associated toxicity and biocompatibility, and successfully safer designed GO for biomedical applications. We prepared a series of $\mathrm{GO}$ derivatives (GO-NH $\mathrm{NH}_{2}, \mathrm{GO}-\mathrm{PAM}$, GO-PAA and GO-PEG) using the same parental GO, to obtain improved biocompatibility and to unravel the molecular mechanisms responsible for the interactions between GO materials and biomolecules. On the one hand, we deciphered the different components in protein corona, which determined the adsorption onto membrane and consequential uptake by macrophages. Among them, we demonstrated differential interactions between IgG and GO materials and the important role of $\mathrm{IgG}$ in protein corona that primarily affected the uptake of GO by macrophages. On the other hand, stronger association with the plasma membrane (such as pristine GO and GO-PAM) was associated with significant damages to cellular membrane (evidenced by enhanced levels of LDH release and disordered ion channels, Figure 7 and 8 and Figure S7-S10) in macrophages and pronounced toxicities in mice, e.g., pro-inflammatory responses and fibrosis (Figure 10 and Figure S11-S17). Furthermore, we unraveled (at least partially) the molecular mechanism responsible for cell membrane impairments induced by GO through genome-wide gene expression analysis. Quite a few membrane- and cytoskeleton-associated genes (e.g., focal adhesion components) were identified to be disorderedly expressed in response to GO treatment. Altogether, we could conclude that GO treatment significantly altered the expression of membrane/cytoskeleton-related genes, and deregulation of these genes greatly contributed to GO-elicited damages to cell membrane. These differences between the surface-modified GOs and the pristine GO determined their differential biological effects such as cell membrane perturbation, platelet depletion in blood, thrombus formation under short-term exposure and the pro-inflammatory effects under long-term exposure. Compared to PEG that is moderately safer than the pristine GO in vivo, we found surface modification by PAA polymer had the greatest biocompatibility in vivo, while PAM polymer modification exhibited the most significant toxic effects in vitro and in vivo, similar to pristine GO. Thus, PAAmodification may represent a safer design feature for GO to improve its biocompatibility and usage in future biomedical applications.

\section{METHODS AND EXPERIMENTAL SECTION}

Preparation of GO Materials. GO was synthesized from graphite (purchased from Qingdao BCSM. Co., Ltd. China) by the modified Hummers' method. ${ }^{24}$ Briefly, $5 \mathrm{~g}$ of graphite powder was added into $120 \mathrm{~mL} \mathrm{H}_{2} \mathrm{SO}_{4}(98 \%)$ at $4{ }^{\circ} \mathrm{C}$. Then, $30 \mathrm{~g}$ of $\mathrm{KMnO}_{4}$ was slowly added while stirring, and the mixture was maintained at $35{ }^{\circ} \mathrm{C}$ for 30 min. Afterward, $230 \mathrm{~mL}$ of $\mathrm{H}_{2} \mathrm{O}$ was carefully added and maintained at $98{ }^{\circ} \mathrm{C}$. After $15 \mathrm{~min}, 500 \mathrm{~mL}$ of $\mathrm{H}_{2} \mathrm{O}$ and $10 \mathrm{~mL}$ of $\mathrm{H}_{2} \mathrm{O}_{2}(30 \%)$ were added. The mixture was filtered and washed with $1: 10 \mathrm{HCl}$ aqueous solution to remove metal ions. Finally, the mixture was filtered and washed with deionized $\mathrm{H}_{2} \mathrm{O}$ until $\mathrm{pH}$ reached 7 , and then dried at 65 ${ }^{\circ} \mathrm{C}$ in vacuum. GO- $\mathrm{NH}_{2}$ was prepared with $\mathrm{GO}$ dispersion in ammonia with hydrazine hydrate as a reducing agent, as described previously. ${ }^{25,26}$ The $\mathrm{pH}$ of GO solution $(0.5 \mathrm{mg} / \mathrm{mL})$ was adjusted to 10 with ammonia solution $\left(28 \% \mathrm{NH}_{3}\right.$ in $\left.\mathrm{H}_{2} \mathrm{O}\right)$, and the mixture after addition of $100 \mu \mathrm{L}$ of hydrazine hydrate $(80 \%)$ was incubated at 
$95{ }^{\circ} \mathrm{C}$ for $1 \mathrm{~h}$. The resultant GO- $\mathrm{NH}_{2}$ solution was dialyzed in deionized water for 7 days to remove the excess ammonia.

GO-PAM and GO-PAA were synthesized, as reported previously. ${ }^{23}$ In brief, GO $(100 \mathrm{mg})$ was refluxed in $\mathrm{H}_{2} \mathrm{O}(200 \mathrm{~mL})$ in the presence of $\mathrm{NaBH}_{4}(2 \mathrm{~g})$ at $80{ }^{\circ} \mathrm{C}$ for $4 \mathrm{~h}$. Thereafter, $5 \mathrm{~g}$ of acrylic acid or acrylamide in $200 \mathrm{~mL}$ of $\mathrm{H}_{2} \mathrm{O}$ were added into the flask, respectively. After stirring for $30 \mathrm{~min}$, the solution was purged under $\mathrm{N}_{2}$ gas for 30 min to remove $\mathrm{O}_{2}$. Then, $80 \mathrm{~mL}$ of $\left(\mathrm{NH}_{4}\right)_{2} \mathrm{~S}_{2} \mathrm{O}_{8}$ solution $(1.25 \mathrm{~g} / \mathrm{L})$ was added through a dropping funnel. The flask was placed in a thermostated oil bath at $80{ }^{\circ} \mathrm{C}$ under stirring. After $48 \mathrm{~h}$, the mixture was cooled down to room temperature, and dialyzed in deionized water for 7 days to remove free PAA and PAM in solution.

GO-PEG was made following the method, as previously described. ${ }^{27}$ Briefly, $10 \mathrm{~mL}$ of $\mathrm{NaOH}(3 \mathrm{~mol} / \mathrm{L})$ was added to 20 $\mathrm{mL}$ of $2 \mathrm{mg} / \mathrm{mL} \mathrm{GO}$ solution and sonicated for $3 \mathrm{~h}$. Thereafter, the solution was neutralized with $\mathrm{HCl}$ and filtered. The filter cake was then dispersed in $40 \mathrm{~mL}$ of water, and $80 \mathrm{mg}$ of polyetheylene glycolamine $(5 \mathrm{kDa})$ was added, followed by sonication for $5 \mathrm{~min}$. 1-ethyl-3(3-(dimethylamino)propyl)carbodiimide hydrochloride (EDC) was added into the solution to reach a concentration of $5 \mathrm{mM}$, followed by sonication for $30 \mathrm{~min}$. Afterward, the concentration of EDC was increased to $20 \mathrm{mM}$ under stirring for another $12 \mathrm{~h}$. The reaction is terminated by adding 2-mercaptoethanol. Finally, all GO materials were dispersed in sterilized deionized water to prepare the stock solution $(0.5$ or $1 \mathrm{mg} / \mathrm{mL})$ for later characterization and experiments.

Characterization of GO Materials. $\zeta$-potential of GO materials in deionized water, PBS and cell culture media was determined using a Zetasizer (Malvern Nano series, Malvern, U.K.). The FT-IR spectra of GO materials were recorded on a Nicolet 6700 FT-IR spectrophotometer (Thermo Fisher Scientific Inc., USA) using the $\mathrm{KBr}$ pellet method. UV-vis spectra was measured on a DU800 spectrophotometer (Beckman Coulter Inc., USA) in $1 \mathrm{~cm}$ quartz cuvettes over the range of 200-800 nm. TEM analysis was performed on an H-7500 transmission electron microscope (Hitachi Scientific Instruments, Japan). The TEM samples were prepared by depositing a small drop of solution onto a carbon-coated copper electron microscopy grid (Beijing Zhongjingkeyi Technology Co., Ltd., China) and then dried under room temperature. SEM/EDS analysis was performed on a Hitachi S-3000N instrument (Hitachi Ltd., Japan) operated at $15 \mathrm{kV}$. To prepare the SEM samples, a small drop of solution was deposited on silicon wafers (Beijing Zhongjingkeyi Technology Co., Ltd., China) and then dried under room temperature. ICP-MS analysis was performed on an Agilent 7500 instrument (Agilent, Tokyo, Japan). With respect to XPS determination, GO samples were deposited onto silicon wafers, air-dried, and then the silicon wafers were subjected to a $\mathrm{X}$-ray photoelection spectroscopy. Raman spectra was recorded using an InVia Raman microscope (Renishaw, UK), equipped with 532, 633, and $785 \mathrm{~nm}$ laser lines as the excitation source. TGA analysis was performed on an SDT Q600 thermobalance (TA Instruments) under nitrogen gas flow $(100 \mathrm{~mL} / \mathrm{min})$ at a heating rate of $10{ }^{\circ} \mathrm{C} / \mathrm{min}$ using alumina crucibles.

AFM images were taken on an AFM 5500 in the contact mode (Agilent Technologies, Inc., USA). The AFM samples were prepared by depositing their dispersions on mica substrates (Beijing Zhongjingkeyi Technology Co., Ltd., China) and then dried under room temperature. To observe the morphological changes of GO samples in cell culture medium, a concentration of $30 \mu \mathrm{g} / \mathrm{mL} \mathrm{GO}$ solution were prepared in Dulbecco's modified Eagle medium (DMEM, Gibco BRL Life Technologies Inc., USA) containing 10\% fetal bovine serum (FBS). After 1 h-incubation at $37^{\circ} \mathrm{C}$, the GO samples were collected by centrifugation $(30 \mathrm{~min}, 12000 \mathrm{~g})$ and repeatedly washed with deionized water for three times. Finally, the obtained GO samples were dispersed in deionized water and analyzed by AFM, as described above.

CD Spectra Analysis of Interaction between Mouse IgG and GO Materials. To access the interaction between mouse IgG and GO, $\mathrm{CD}$ spectra was performed. The CD spectra was acquired on a J-815 spectropolarimeter (Jasco, Japan) using a $1 \mathrm{~mm}$ path length quartz cell for the near- and far-UV range measurements at room temperature. The data were collected from 190 to $250 \mathrm{~nm}$ using a response time of
$1 \mathrm{~s}$ and a scan speed of $100 \mathrm{~nm} / \mathrm{min}$. Spectra represented an average of three scans with the background corrected against a buffer blank (deionized water). Calculated volumes of GO, GO-NH$H_{2}, \mathrm{GO}-\mathrm{PAM}$, GO-PAA or GO-PEG solutions were added into mouse IgG solution $(0.125 \mathrm{mg} / \mathrm{mL}$, Sigma-Aldrich) at a final concentration of 8,30 , or 60 $\mu \mathrm{g} / \mathrm{mL}$. Data were then collected and quantitatively analyzed for the secondary structure with a Spectra Manager II software provided by instrument manufacturer.

Cell Culture. Murine macrophage cell line J774A.1 was obtained from the Shanghai Cell Bank of Type Culture Collection of China. Cells were cultured in DMEM (Gibco BRL Life Technologies Inc., USA) with $10 \% \mathrm{FBS}$, and 100 units $/ \mathrm{mL}$ penicillin/streptomycin (Invitrogen).

Cytotoxicity Assay. For cytotoxicity assay, $1 \times 10^{4}$ or $2 \times 10^{5}$ J774A.1 cells/well were seeded in 96- or 24-well plates, respectively, and incubated in a humidified 5\% $\mathrm{CO}_{2}$-balanced air incubator at 37 ${ }^{\circ} \mathrm{C}$. Thereafter, cells were treated with different GO samples (GO, GO-NH ${ }_{2}$, GO-PAM, GO-PAA and GO-PEG) at 1, 2, 4, 10, 20, 50, 100 , or $200 \mu \mathrm{g} / \mathrm{mL}$, followed by toxicity assessments after $24 \mathrm{~h}$. Cytotoxicity was evaluated by cell number counting from 24-well plates, and cell viability was determined through $\mathrm{AB}$ assay and CCK- 8 assay with 96-well plates following the instructions from the manufacturers (Sigma-Aldrich, USA and Shanghai Sangon Biological Engineering Technology and Service Co., China, respectively). Cell density and morphology were visualized and imaged with an Axiovert 40 CFL phase-contrast microscope (Carl Zeiss, Inc., Germany).

Cellular Localization of GO through TEM. For TEM analysis, 2 $\times 10^{6} \mathrm{~J} 774 \mathrm{~A} .1$ cells were seeded in $6 \mathrm{~cm}$ plates. Then, the cells were exposed to GO samples (GO, GO-NH $\mathrm{N}_{2}$, GO-PAM, GO-PAA and GO$\mathrm{PEG}$ ) at $4 \mu \mathrm{g} / \mathrm{mL}$, and incubated in a humidified $5 \% \mathrm{CO}_{2}$-balanced air incubator at $37^{\circ} \mathrm{C}$. After $24 \mathrm{~h}$, the cells were collected at $1000 \mathrm{rpm}$ for $3 \mathrm{~min}$, and repeatedly washed with PBS for three times. The harvested cells were fixed with $2.5 \%$ glutaraldehyde solution and embedded with epoxy resin. The ultrathin cell specimens $(70 \mathrm{~nm})$ were placed on the grids, stained with $1 \%$ lead citrate and $0.5 \%$ uranyl acetate and then examined with TEM. Intracellular localization of GO sheets was studied using a high-resolution JEOL JEM 2010F transmission electron microscope (Hitachi Scientific Instruments, Japan).

Cellular Adhesion and Uptake through Confocal Fluorescence Microscopy and Flow Cytometry. To define the interaction between GO and macrophages, FITC-BSA (Bioss Inc., China) labeled GO samples was prepared for cell treatment. FITC-BSA was labeled on GO materials using an established method, as described previously. ${ }^{35,36,49}$ Labeled GO samples were washed with PBS for 3 times to remove free FITC-BSA. For confocal analysis, $1 \times 10^{6}$ J774A.1 cells were seeded in $3.5 \mathrm{~cm}$ confocal dish, and FITC-BSA labeled GO was then added at a final concentration of $4 \mu \mathrm{g} / \mathrm{mL}$. After $24 \mathrm{~h}$ exposure, cells were fixed with $4 \%$ paraformaldehyde in PBS for $10 \mathrm{~min}$, and then stained with DAPI (blue) and Rhodamine-phalloidin (red). The fluorescence of DAPI and Rhodamine-phalloidin were excited at 364 and $540 \mathrm{~nm}$, and observed at $419-493 \mathrm{~nm}$ and 550$650 \mathrm{~nm}$, respectively, using a TCS SP5 laser scanning confocal microscope (Leica, Germany). FITC fluorescence was excited at 488 $\mathrm{nm}$ and measured at $500-800 \mathrm{~nm}$.

In order to quantitatively evaluate the cellular adhesion and uptake of GO, cells $\left(2 \times 10^{4}\right.$ cells $)$ after treatment with FITC-BSA GO were also subjected to flow cytometry analysis using a NovoCyte 1040 flow cytometry at $526 \mathrm{~nm}$ with excitation wavelength at $506 \mathrm{~nm}$ (ACEA BIO, China), as previously described. ${ }^{36}$

Protein Corona Analysis by Mass Spectrometry. First, $25 \mu \mathrm{g}$ differential GO samples were individually added into $500 \mu \mathrm{L}$ of mouse serum (EMD Millipore Corporation, USA) and incubated at $37^{\circ} \mathrm{C}$ for $1 \mathrm{~h}$ to allow the formation of protein corona. After incubation, GO samples were spun down at $12,000 \mathrm{~g}$ for $15 \mathrm{~min}$, and the supernatants were carefully aspirated. GO pellets were repeatedly washed and centrifuged to remove excess proteins. As a control, an equal volume of serum without particles was applied in parallel. Finally, the protein corona on GO particles was stripped in $30 \mu \mathrm{L}$ SDS-PAGE sample buffer (Solarbio Science \& Technology Co., Ltd., Beijing, China), and then separated by SDS-PAGE and visualized by coomassie brilliant 
blue staining method. Protein bands in gels were then imaged using a Bio-Rad ChemiDoc XRS system (Bio-Rad Inc., CA, USA) and quantitatively analyzed by the Image Lab software provided by the manufacturer.

To characterize the composition of protein coronas, the selected protein bands were excised from the gels, destained and in-gel digested according to a standard protocol. ${ }^{50}$ The excised pieces were washed with $1000 \mu \mathrm{L}$ of $\mathrm{H}_{2} \mathrm{O}$ for $10 \mathrm{~min}$, and then three times with $25 \mathrm{mM}$ $\mathrm{NH}_{4} \mathrm{HCO}_{3}, 50 \%$ acetonitrile (ACN) until the blue color disappeared. After washing with $100 \% \mathrm{ACN}$ and air drying, $10 \mathrm{mM}$ DTT solution was added for reduction at $56^{\circ} \mathrm{C}$ for $1 \mathrm{~h}$. Afterward, the DTT solution was removed and $55 \mathrm{mM}$ iodoacetamide was added for another 45 min incubation in the dark at room temperature. The gel pieces were then washed with $25 \mathrm{mM} \mathrm{NH}_{4} \mathrm{HCO}_{3}, 50 \%$ acetonitrile and dehydrated with $100 \%$ ACN. Finally, a volume of $20 \mu \mathrm{L}$ trypsin solution $(1 \mu \mathrm{g} / \mu \mathrm{L}$, proteomics grade, Sigma-Aldrich) was added for overnight incubation at $37^{\circ} \mathrm{C}$. The enzymatic hydrolysis was terminated by the addition of $0.1 \%$ formic acid (FA).

After digestion, $10 \mu \mathrm{L}$ peptide mixtures were analyzed by HPLCESI-MS/MS using a microTOF-II mass spectrometry system (Bruker Daltonics, USA). For peptide separation, the mixtures were applied on a $\mathrm{C} 18$ reverse phase column (Eprogen, USA) with $\mathrm{H}_{2} \mathrm{O}\left(\mathrm{A}: \mathrm{H}_{2} \mathrm{O}\right.$, $0.1 \% \mathrm{FA}$ ) and $\mathrm{ACN}$ (B: $\mathrm{ACN}, 0.1 \% \mathrm{FA}$ ) as eluants. Thereafter, an elution program (0-4 min: $5 \% \mathrm{~B}$; $4-30 \mathrm{~min}$ : $5 \%-40 \% \mathrm{~B}$; $30-35 \mathrm{~min}$ : $40 \%-80 \% \mathrm{~B}$; $35-45 \mathrm{~min}: 80 \%$ B) was executed on a prominence nano 2D HPLC system (Shimazhu, Japan) with a flow rate of $400 \mathrm{~nL} /$ $\mathrm{min}$. The MS was operated in the positive ion mode and the $\mathrm{m} / z 50$ to 2000 range was scanned. The spray voltage and capillary temperature were set at $1.5 \mathrm{kV}$ and $150{ }^{\circ} \mathrm{C}$, respectively. For protein identification, raw data files were converted to Mascot generic format (mgf) files and searched in National Center for Biotechnology Information (NCBInr) database via Mascot Search (version 2.3.01, Matrix Science, http:// www.matrixscience.com/). Mascot searching parameters included trypsin as the proteolytic enzyme with one missed cleavage. The modifications of methionine oxidation were selected. Peptide charge was set to $+1,+2$ and +3 . A minimal Mascot score of 50 was set for protein identity validation.

Membrane Permeability Assay. To evaluate membrane permeability, $1 \times 10^{6}$ cells were seeded in $3.5 \mathrm{~cm}$ confocal dish, and GO samples were added at a final concentration of $4 \mu \mathrm{g} / \mathrm{mL}$. After 24 $\mathrm{h}$ exposure, cells were washed with $\mathrm{PBS}$, and immediately stained with PI at $0.05 \mathrm{mg} / \mathrm{mL}$ in PBS. After $5 \mathrm{~min}$ incubation in the dark at $4{ }^{\circ} \mathrm{C}$, PI fluorescence was visualized using a TCS SP5 confocal laser scanning confocal microscope at $535 \mathrm{~nm}$ with the excitation wavelength at 617 nm.

Leakage of LDH from cells was assayed to determine the effect of GO on cell membrane permeability. Briefly, $1 \times 10^{4}$ cells/well were seeded in 96-well plate, and exposed to GO materials at 1, 2, 4, 6, 8, 10,50 , and $100 \mu \mathrm{g} / \mathrm{mL}$. After cell treatment for $24 \mathrm{~h}$, cell culture medium was collected from each well, and centrifuged and collected for the following assessment using a commercial LDH kit (Nanjing Jiancheng Bioengineering Institute, China). Absorbance was measured at $490 \mathrm{~nm}$ on a Varioskan Flash Multimode plate reader.

$\mathrm{Ca}^{2+}$ Flux Assay. Changes of intracellular $\mathrm{Ca}^{2+}$ were monitored using Fluo-3/AM fluorescence probe (Dojindo Molecular Technologies, Inc., Japan). Briefly, $1 \times 10^{5}$ cells were incubated at $37^{\circ} \mathrm{C}$ in the dark with $4 \mu \mathrm{M}$ Fluo-3/AM for $20 \mathrm{~min}$. Afterward, cells were washed for three times and resuspended in Hank's Balanced Salt Solutions. Thereafter, cells were treated with GO samples at $4 \mu \mathrm{g} / \mathrm{mL}$, and then analyzed using a NovoCyte 1040 flow cytometry at $526 \mathrm{~nm}$ with excitation wavelength at $506 \mathrm{~nm}$ (ACEA BIO, China).

Membrane Fluidity Assay. Trimethylammonium diphenylhexatriene (TMA-DPH, Dojindo, Japan) was used to assess membrane fluidity. In brief, cells $\left(1 \times 10^{4}\right.$ cells per well in 96-well plate) were incubated with $5 \mu \mathrm{mol} / \mathrm{L}$ TMA-DPH in Hepes buffer at $37{ }^{\circ} \mathrm{C}$ for 5 $\min$. The fluorescence intensity of TMA-DPH was first measured for 5 min using a Varioskan Flash Multimode Reader (excitation wavelength: $355 \mathrm{~nm}$ and emission wavelength: $430 \mathrm{~nm}$ ). Following the addition of GO samples at $4 \mu \mathrm{g} / \mathrm{mL}$, the fluorescence intensity was continuously recorded for $60 \mathrm{~min}$.
RNA-Seq Transcriptome Analysis. Total RNAs were isolated from cells after GO exposure at $4 \mu \mathrm{g} / \mathrm{mL}$ for 1,6 , and $24 \mathrm{~h}$. RNA-seq and data analysis were performed by the BGI Co., Ltd. (China). Fold changes at either 2 -fold greater or fewer than 0.5 -fold in GO-treated cells compared to untreated cells, a false discovery rate (FDR) $\leq 0.001$ and an absolute value of $\log 2$ Ratio $\geq 1$ were used as thresholds to determine the significance of the gene expression difference. Gene Ontology analysis was carried out using the GO database (http:// geneontology.org/).

Animal Experimentation. Male BALB/c mice (7-8 weeks old with body weight around $20 \mathrm{~g}$ ) were purchased from the Vital River laboratories (Beijing, China). All animals were maintained and used in accordance with the Guidelines of the Animal Ethics Committee at the Research Center for Eco-Environmental Sciences, Chinese Academy of Sciences. For in vivo toxicity evaluation, mice were administrated with GO samples via a single intratail vein injection in a total volume of $100 \mu \mathrm{L}$ at indicated concentrations $(n=10)$. Post administration, their survival rate and body weights were recorded every 2 days for 2 weeks. For control group, mice received PBS only.

Complete Blood Count Assay. For complete blood count analysis, $20 \mu \mathrm{L}$ fresh blood was immediately diluted in $2 \mathrm{~mL}$ diluent buffer. Blood parameters including the numbers of RBC, WBC, PLT, neutrophils, lymphocyte and the content of hemoglobin were measured using a MEK-7222K automated hematology analyzer (Nihon Kohden, Japan).

Blood Biochemistry Assay. The activities of ALT and AST in mouse sera were determined with kits from Nanjing Jiancheng Bioengineering Institute, China. The concentrations of IL- 6 and TNF$\alpha$ were quantitatively assayed in sera with kits from OriGene Technologies, China.

GO Distribution Assay in Mice. To understand the in vivo biodistribution of GO, organs were collected after mice were sacrificed post GO administration at $2 \mathrm{mg} / \mathrm{kg}$ body weight for 1 day. Organs (including lung, liver, spleen, kidney, heart and brain) were immediately frozen by liquid nitrogen. Thereafter, organs were fixed, sectioned and imaged using the LDI IMS, as described previously. ${ }^{47}$

Histological Examination. When mice were sacrificed, tissue specimens were immediately collected and fixed with $10 \%$ formalin in PBS. Tissues were embedded in a paraffin block, and then sliced into 5 $\mu \mathrm{m}$ thick sections onto glass slides. Following standard protocols, $\mathrm{H} \& \mathrm{E}$ and Masson's trichrome staining was performed. Slides were observed and imaged with an Axio Scope Al optical microscope (Carl Zeiss, Inc., Germany).

Western Blot Analysis. Lung tissues were homogenized for total protein extraction using a SCIENTZ-48 tissuelyser kit (Ningbo Scientz Biotech Co Ltd., China). Protein concentrations were determined with the Lowry method (Solarbio Science \& Technology Co., Ltd., Beijing, China). Equal amounts of proteins were subjected to SDS-PAGE and Western blotting according to the established method. ${ }^{36}$ The primary Abs were: antimouse collagen 1; antimouse Gr 1; antimouse CD68; antimouse CD11b and antimouse GAPDH (1:500 or 1:1000 dilutions, Abcam, Inc.). Western blotting signals were detected using a BIO-RAD ChemiDoc XRS chemiluminescence system (Bio-Rad Inc., CA, USA). The intensity of autoradiogram for Western blot was quantified using Image Lab software. The band intensity was normalized to that of the landing control.

Statistical Analysis. Data were represented as the mean \pm standard deviation. Statistical analysis was performed using the Student's $t$-test. $P<0.05$ was considered to be statistically significant.

\section{ASSOCIATED CONTENT}

\section{Supporting Information}

The Supporting Information is available free of charge on the ACS Publications website at DOI: 10.1021/acsnano.6b00539.

Characterization properties, cytotoxicity assay, membrane permeability assay, $\mathrm{Ca}^{2+}$ flux assay, membrane fluidity assay, survival rate and body weight change, complete blood count analysis, histological assays, 
Western blot analysis, biochemical analysis and proteins identification information. (PDF)

\section{AUTHOR INFORMATION}

\section{Corresponding Authors}

*Tel: 8610-62849330. E-mail: jweng@xmu.edu.cn.

*E-mail: drzhangzhihong@163.com.

*E-mail: sjliu@rcees.ac.cn.

\section{Author Contributions}

${ }^{\#}$ M.X. and J.Z. contributed equally to this work.

Notes

The authors declare no competing financial interest.

\section{ACKNOWLEDGMENTS}

This work was supported by grants under the national "973" program (Grant Number: 2014CB932000, 2015CB931900) and the Strategic Priority Research Program of the Chinese Academy of Sciences (Grant No. XDB14000000), grants from the National Natural Science Foundation of China (Grant Numbers: 21407169, 21425731, 21377159, 21177151, 21207152). We thank Dr. Zongxiu Nie for great assistance with LDI IMS analysis. We thank all the laboratory members for their great assistance with experiments and reagents.

\section{REFERENCES}

(1) Novoselov, K. S.; Fal'ko, V. I.; Colombo, L.; Gellert, P. R.; Schwab, M. G.; Kim, K. A Roadmap for Graphene. Nature 2012, 490, 192-200.

(2) Zurutuza, A.; Marinelli, C. Challenges and Opportunities in Graphene Commercialization. Nat. Nanotechnol. 2014, 9, 730-734.

(3) Kostarelos, K.; Novoselov, K. S. Exploring the Interface of Graphene and Biology. Science 2014, 344, 261-263.

(4) Wick, P.; Louw-Gaume, A. E.; Kucki, M.; Krug, H. F.; Kostarelos, K.; Fadeel, B.; Dawson, K. A.; Salvati, A.; Vázquez, E.; Ballerini, L.; Tretiach, M.; Benfenati, F.; Flahaut, E.; Gauthier, L.; Prato, M.; Bianco, A. Classification Framework for Graphene-Based Materials. Angew. Chem., Int. Ed. 2013, 52, 4986-4997.

(5) Yang, K.; Feng, L.; Shi, X.; Liu, Z. Nano-Graphene in Biomedicine: Theranostic Applications. Chem. Soc. Rev. 2013, 42, 530-547.

(6) Bitounis, D.; Ali-Boucetta, H.; Hong, B. H.; Min, D. H.; Kostarelos, K. Prospects and Challenges of Graphene in Biomedical Applications. Adv. Mater. 2013, 25, 2258-2268.

(7) Hu, W.; Peng, C.; Luo, W.; Lv, M.; Li, X.; Li, D.; Huang, Q.; Fan, C. Graphene-Based Antibacterial Paper. ACS Nano 2010, 4, 43174323.

(8) Akhavan, O.; Ghaderi, E. Toxicity of Graphene and Graphene Oxide Nanowalls Against Bacteria. ACS Nano 2010, 4, 5731-5736.

(9) Liu, S.; Zeng, T. H.; Hofmann, M.; Burcombe, E.; Wei, J.; Jiang, R.; Kong, J.; Chen, Y. Antibacterial Activity of Graphite, Graphite Oxide, Graphene Oxide, and Reduced Graphene Oxide: Membrane and Oxidative Stress. ACS Nano 2011, 5, 6971-6980.

(10) Duch, M. C.; Budinger, G. R. S.; Liang, Y. T.; Soberanes, S.; Urich, D.; Chiarella, S. E.; Campochiaro, L. A.; Gonzalez, A.; Chandel, N. S.; Hersam, M. C.; Mutlu, G. M. Minimizing Oxidation and Stable Nanoscale Dispersion Improves the Biocompatibility of Graphene in the Lung. Nano Lett. 2011, 11, 5201-5207.

(11) Singh, S. K.; Singh, M. K.; Kulkarni, P. P.; Sonkar, V. K.; Grácio, J. J.; Dash, D. Amine-Modified Graphene: Thrombo-Protective Safer Alternative to Graphene Oxide for Biomedical Applications. ACS Nano 2012, 6, 2731-2740.

(12) Liu, J. H.; Yang, S. T.; Wang, H.; Chang, Y.; Cao, A.; Liu, Y. Effect of Size and Dose on the Biodistribution of Graphene Oxide in Mice. Nanomedicine 2012, 7, 1801-1812.
(13) Chatterjee, N.; Eom, H. J.; Choi, J. A Systems Toxicology Approach to the Surface Functionality Control of Graphene-Cell Interactions. Biomaterials 2014, 35, 1109-1127.

(14) Seabra, A. B.; Paula, A. J.; de Lima, R.; Alves, O. L.; Durán, N. Nanotoxicity of Graphene and Graphene Oxide. Chem. Res. Toxicol. 2014, 27, 159-168.

(15) Fu, C.; Liu, T.; Li, L.; Liu, H.; Liang, Q.; Meng, X. Effects of Graphene Oxide on the Development of Offspring Mice in Lactation Period. Biomaterials 2015, 40, 23-31.

(16) Nel, A. E.; Mädler, L.; Velegol, D.; Xia, T.; Hoek, E. M. V.; Somasundaran, P.; Klaessig, F.; Castranova, V.; Thompson, M. Understanding Biophysicochemical Interactions at the Nano-Bio Interface. Nat. Mater. 2009, 8, 543-557.

(17) Aggarwal, P.; Hall, J. B.; McLeland, C. B.; Dobrovolskaia, M. A.; McNeil, S. E. Nanoparticle Interaction with Plasma Proteins as It Relates to Particle Biodistribution, Biocompatibility and Therapeutic Efficacy. Adv. Drug Delivery Rev. 2009, 61, 428-437.

(18) Miao, W.; Shim, G.; Lee, S.; Lee, S.; Choe, Y. S.; Oh, Y. K. Safety and Tumor Tissue Accumulation of Pegylated Graphene Oxide Nanosheets for Co-Delivery of Anticancer Drug and Photosensitizer. Biomaterials 2013, 34, 3402-3410.

(19) Knop, K.; Hoogenboom, R.; Fischer, D.; Schubert, U. S. Poly(Ethylene Glycol) in Drug Delivery: Pros and Cons as Well as Potential Alternatives. Angew. Chem., Int. Ed. 2010, 49, 6288-6308.

(20) Kontos, S.; Hubbell, J. A. Drug Development: Longer-Lived Proteins. Chem. Soc. Rev. 2012, 41, 2686-2695.

(21) Yang, W.; Liu, S.; Bai, T.; Keefe, A. J.; Zhang, L.; Ella-Menye, J. R.; Li, Y.; Jiang, S. Poly(Carboxybetaine) Nanomaterials Enable Long Circulation and Prevent Polymer-Specific Antibody Production. Nano Today 2014, 9, 10-16.

(22) Yang, K.; Li, Y.; Tan, X.; Peng, R; Liu, Z. Behavior and Toxicity of Graphene and Its Functionalized Derivatives in Biological Systems. Small 2013, 9, 1492-1503.

(23) Dong, J.; Ding, J.; Weng, J.; Dai, L. Graphene Enhances the Shape Memory of Poly(Acrylamide-Co-Acrylic acid) Grafted on Graphene. Macromol. Rapid Commun. 2013, 34, 659-664.

(24) Kovtyukhova, N. I.; Ollivier, P. J.; Martin, B. R.; Mallouk, T. E.; Chizhik, S. A.; Buzaneva, E. V.; Gorchinskiy, A. D. Layer-by-Layer Assembly of Ultrathin Composite Films from Micron-Sized Graphite Oxide Sheets and Polycations. Chem. Mater. 1999, 11, 771-778.

(25) Li, D.; Müller, M. B.; Gilje, S.; Kaner, R. B.; Wallace, G. G. Processable Aqueous Dispersions of Graphene Nanosheets. Nat. Nanotechnol. 2008, 3, 101-105.

(26) Jia, J.; Sun, L.; Hu, N.; Huang, G.; Weng, J. Graphene Enhances the Specificity of the Polymerase Chain Reaction. Small 2012, 8, 2011-2015.

(27) Liu, Z.; Robinson, J. T.; Sun, X.; Dai, H. PEGylated Nanographene Oxide for Delivery of Water-Insoluble Cancer Drugs. J. Am. Chem. Soc. 2008, 130, 10876-10877.

(28) Tenzer, S.; Docter, D.; Kuharev, J.; Musyanovych, A.; Fetz, V.; Hecht, R.; Schlenk, F.; Fischer, D.; Kiouptsi, K.; Reinhardt, C.; Landfester, K.; Schild, H.; Maskos, M.; Knauer, S. K.; Stauber, R. H. Rapid Formation of Plasma Protein Corona Critically Affects Nanoparticle Pathophysiology. Nat. Nanotechnol. 2013, 8, 772-781.

(29) Cukalevski, R.; Ferreira, S. A.; Dunning, C. J.; Berggård, T.; Cedervall, T. IgG and Fibrinogen Driven Nanoparticle Aggregation. Nano Res. 2015, 8, 2733-2743.

(30) Zhu, Y.; Li, W.; Li, Q.; Li, Y.; Li, Y.; Zhang, X.; Huang, Q. Effects of Serum Proteins on Intracellular Uptake and Cytotoxicity of Carbon Nanoparticles. Carbon 2009, 47, 1351-1358.

(31) Ge, C.; Du, J.; Zhao, L.; Wang, L.; Liu, Y.; Li, D.; Yang, Y.; Zhou, R.; Zhao, Y.; Chai, Z.; Chen, C. Binding of Blood Proteins to Carbon Nanotubes Reduces Cytotoxicity. Proc. Natl. Acad. Sci. U. S. A. 2011, 108, 16968-16973.

(32) Hu, W.; Peng, C.; Lv, M.; Li, X.; Zhang, Y.; Chen, N.; Fan, C.; Huang, Q. Protein Corona-Mediated Mitigation of Cytotoxicity of Graphene Oxide. ACS Nano 2011, 5, 3693-3700.

(33) Guan, G.; Kang, S.; Tian, X.; Grate, J. A.; Zhao, L.; Ge, C.; Zhou, R. Protein Corona Mitigates the Cytotoxicity of Graphene 
Oxide by Reducing its Physical Interaction with Cell Membrane. Nanoscale 2015, 7, 15214-15224.

(34) Wu, C.; Wang, C.; Zheng, J.; Luo, C.; Li, Y.; Guo, S.; Zhang, J. Vacuolization in Cytoplasm and Cell Membrane Permeability Enhancement Triggered by Micrometer-Sized Graphene Oxide. ACS Nano 2015, 9, 7913-7924.

(35) Qu, G.; Liu, S.; Zhang, S.; Wang, L.; Wang, X.; Sun, B.; Yin, N.; Gao, X.; Xia, T.; Chen, J. J.; Jiang, G. B. Graphene Oxide Induces Tolllike Receptor 4 (TLR4)-Dependent Necrosis in Macrophages. ACS Nano 2013, 7, 5732-5745.

(36) Ma, J.; Liu, R.; Wang, X.; Liu, Q.; Chen, Y.; Valle, R. P.; Zuo, Y. Y.; Xia, T.; Liu, S. Crucial Role of Lateral Size for Graphene Oxide in Activating Macrophages and Stimulating Pro-inflammatory Responses in Cells and Animals. ACS Nano 2015, 9, 10498-10515.

(37) Wang, K.; Ruan, J.; Song, H.; Zhang, J.; Wo, Y.; Guo, S.; Cui, D. Biocompatibility of Graphene Oxide. Nanoscale Res. Lett. 2011, 6, 8.

(38) Li, Y.; Wu, Q.; Zhao, Y.; Bai, Y.; Chen, P.; Xia, T.; Wang, D. Response of MicroRNAs to In Vitro Treatment with Graphene Oxide. ACS Nano 2014, 8, 2100-2110.

(39) Li, Y.; Feng, L.; Shi, X.; Wang, X.; Yang, Y.; Yang, K.; Liu, T.; Yang, G.; Liu, Z. Surface Coating-Dependent Cytotoxicity and Degradation of Graphene Derivatives: Towards the Design of NonToxic, Degradable Nano-Graphene. Small 2014, 10, 1544-1554.

(40) Cordes, N. Integrin-Mediated Cell-Matrix Interactions for Prosurvival and Antiapoptotic Signaling after Genotoxic Injury. Cancer Lett. 2006, 242, 11-19.

(41) Wickström, S. A.; Fässler, R. Regulation of Membrane Traffic by Integrin Signaling. Trends Cell Biol. 2011, 21, 266-273.

(42) Yi, Y. H.; Chang, Y. S.; Lin, C. H.; Lew, T. S.; Tang, C. Y.; Tseng, W. L.; Tseng, C. P.; Lo, S. J. Integrin-Mediated Membrane Blebbing is Dependent on Sodium-Proton Exchanger 1 and SodiumCalcium Exchanger 1 Activity. J. Biol. Chem. 2012, 287, 10316-10324.

(43) Zhang, X.; Yin, J.; Peng, C.; Hu, W.; Zhu, Z.; Li, W.; Fan, C.; Huang, Q. Distribution and Biocompatibility Studies of Graphene Oxide in Mice after Intravenous Administration. Carbon 2011, 49, 986-995.

(44) Li, B.; Yang, J.; Huang, Q.; Zhang, Y.; Peng, C.; Zhang, Y.; He, Y.; Shi, J.; Li, W.; Hu, J.; Fan, C. Biodistribution and Pulmonary Toxicity of Intratracheally Instilled Graphene Oxide in Mice. NPG Asia Mater. 2013, 5, e44.

(45) Miao, W.; Shim, G.; Lee, S.; Lee, S.; Choe, Y. S.; Oh, Y. K. Safety and Tumor Tissue Accumulation of Pegylated Graphene Oxide Nanosheets for Co-Delivery of Anticancer Drug and Photosensitizer. Biomaterials 2013, 34, 3402-3410.

(46) Fujimi, S.; MacConmara, M. P.; Maung, A. A.; Zang, Y.; Mannick, J. A.; Lederer, J. A.; Lapchak, P. H. Platelet Depletion in Mice Increases Mortality after Thermal Injury. Blood 2006, 107, 4399-4406.

(47) Chen, S.; Xiong, C.; Liu, H.; Wan, Q.; Hou, J.; He, Q.; BaduTawiah, A.; Nie, Z. Mass Spectrometry Imaging Reveals the SubOrgan Distribution of Carbon Nanomaterials. Nat. Nanotechnol. 2015, 10, 176-182.

(48) Zhang, X. D.; Chen, J.; Min, Y.; Park, G. B.; Shen, X.; Song, S. S.; Sun, Y. M.; Wang, H.; Long, W.; Xie, J.; Gao, K.; Zhang, L.; Fan, S.; Fan, F.; Jeong, U. Metabolizable $\mathrm{Bi}_{2} \mathrm{Se}_{3}$ Nanoplates: Biodistribution, Toxicity, and Uses for Cancer Radiation Therapy and Imaging. Adv. Funct. Mater. 2014, 24, 1718-1729.

(49) Mu, Q. X.; Su, G. M.; Li, L. W.; Gilbertson, B. O.; Yu, L. H.; Zhang, Q.; Sun, Y. P.; Yan, B. Size-Dependent Cell Uptake of ProteinCoated Graphene Oxide Nanosheets. ACS Appl. Mater. Interfaces 2012, 4, 2259-2266.

(50) Xu, M.; Bijoux, H.; Gonzalez, P.; Mounicou, S. Investigating the Response of Cuproproteins from Oysters (Crassostrea gigas) after Waterborne Copper Exposure by Metallomic and Proteomic Approaches. Metallomics 2014, 6, 338-346. 